\title{
RISCO DE OCORRÊNCIA DE GEADA NA REGIÃO CENTRO-SUL DO BRASIL
}

WREGE, Marcos Silveira - marcos.wrege@embrapa.br Empresa Brasileira de Pesquisa Agropecuária / EMBRAPA - FLORESTAS

FRITZSONS, Elenice - elenice.fritzsons@embrapa.br Empresa Brasileira de Pesquisa Agropecuária / EMBRAPA - FLORESTAS

SOARES, Márcia Toffani Simão - marcia.toffani@embrapa.br Empresa Brasileira de Pesquisa Agropecuária / EMBRAPA - FLORESTAS

PRELA-PÂNTANO, Angélica - angelica@iac.sp.gov.br Instituto Agronômico / IAC

STEINMETZ, Silvio - silvio.steinmetz@embrapa.br Empresa Brasileira de Pesquisa Agropecuária / EMBRAPA - Clima Temperado

CARAMORI, Paulo Henrique - pcaramori@gmail.com Instituto Agronômico do Paraná / IAPAR

RADIN, Bernardete - bernadete-radin@agricultura.rs.gov.br Secretaria da Agricultura, Pecuária e Irrigação / SEAPI

PANDOLFO, Cristina - cristina@epagri.sc.gov.br Empresa de Pesquisa Agropecuária e Extensão Rural de Santa Catarina/ EPAGRI

\begin{abstract}
RESUMO: A geada é responsável pela maior parte dos sinistros agrícolas no Centro-Sul do Brasil, ocasionando perdas econômicas por longos períodos, principalmente no final do outono e no início da primavera e, por isso, deve ser considerada para a produção agrícola, pecuária e florestal. Este trabalho apresenta mapas de risco de ocorrência de geada nas diferentes zonas climáticas existentes nos estados do Centro-Sul do Brasil, utilizando "distribuição de valores extremos" (Gumbel). Os mapas foram feitos em sistemas geográficos de informações. As geadas foram calculadas usando dados de temperatura mínima no abrigo inferiores a $3^{\circ} \mathrm{C}$. Os riscos foram separados em classes, que permitiram identificar as regiões de maior probabilidade de ocorrência de geada. $A$ região situada entre o sul do Paraná e o norte do Rio Grande do Sul é a de maior risco (maior que 50\%), principalmente nos municípios de maior altitude, enquanto que na região costeira e nos vales de rios os riscos diminuem, em função da menor altitude e maior umidade. Entretanto, na Metade Sul do Rio Grande do Sul, mesmo com altitudes menores, o risco de ocorrência de geadas é alto devido à latitude. Este trabalho pode servir de base para estudos de zoneamento agrícola de riscos climáticos, o qual é importante instrumento de política agrícola para concessão de seguro rural e crédito agrícola.
\end{abstract}

PALAVRAS-CHAVES: riscos climáticos; zoneamento agrícola; planejamento de uso da terra; política agrícola; distribuição de Gumbel.

\section{RISK OF FROST OCCURRENCE IN THE SOUTH CENTER BRAZIL}

ABSTRACT: The frost is responsible for most of the agricultural losses in southern Brazil, causing frequent economic losses mainly in the winter and, therefore, it must be considered for agriculture, livestock and forestry production. This work presents maps of frost risk with minimum screen temperature lower than $3^{\circ} \mathrm{C}$, in the climatic zones of the southern states of Brazil and in the State of São Paulo, using Gumbel distribution. The region located between southern Paraná and northern Rio Grande do Sul States presents 
higher risk (above 50\%), especially in municipalities with higher altitudes, while in the coastal region and river valleys the risk decreases due to the lower altitude. However, in the southern half of the State of Rio Grande do Sul, even at low altitudes, the risk of frost occurrence is high due to latitude. The present study can serve as a basis for agricultural zoning studies of climatic risks, which are important agricultural policy instruments for the granting of rural insurance and agricultural credit.

KEYWORDS: Climatic risks; Agricultural zoning; Land use planning; Agricultural policy; Gumbel distribution

\section{RIESGO DE OCURRENCIA DE GEADA EN LA REGIÓN CENTRO-SUR DE BRASIL}

RESUMEN: El riesgo de heladas es el responsable de la mayor parte de los siniestros agrícolas en el centro-sur de Brasil, ocasionando pérdidas económicas en un gran número de años, principalmente en el invierno $y$, por eso, debe ser considerado para la producción agrícola, pecuaria y forestal. Este trabajo presenta mapas de riesgo de ocurrencia de heladas en las diferentes zonas climáticas existentes en los estados del centro-sur de Brasil, utilizando distribución de Gumbel. Las heladas se calcularon utilizando datos de temperatura mínima en el abrigo inferior a $3^{\circ} \mathrm{C}$. Se separaron locales con riesgo mayor que $50 \%$ y $60 \%$ de ocurrencia de heladas, es decir, cada 10 años había más de cinco o seis años con al menos una helada en julio. La región situada entre el sur de Paraná y el norte de Rio Grande do Sul es la de mayor riesgo (por encima del $50 \%$ ), principalmente en los municipios de mayor altitud, mientras que la región costera y en los valles de ríos los riesgos disminuyen, en función de la menor altitud y mayor humedad. Sin embargo, en la Mitad Sur de Rio Grande do Sul, incluso con altitudes menores, el riesgo de ocurrencia de heladas es alto debido a la latitud. Este trabajo sirve de base para estudios de zonificación agrícola de riesgos climáticos, que son importantes instrumentos de política agrícola para concesión de seguro y crédito agrícola.

PALABRAS CLAVE: riesgos climáticos; zonificación agrícola; planificación de uso de la tierra; política agrícola; distribución de Gumbel.

\section{RISQUE DE PRÉSENCE DE GELÉE DANS LA RÉGION CENTRE-SUD DU BRÉSIL}

RÉSUMÉ: Le risque de gel est responsable de la plupart des pertes agricoles dans le centre-sud du Brésil, causant des pertes économiques dans un grand nombre d'années, principalement en hiver et, par conséquent, devrait être considéré pour la production agricole, animale et forestière. Ce travail présente des cartes des risques de gel dans différentes zones climatiques des états du centre-sud du Brésil, en utilisant la distribution de Gumbel. Les gelées ont été calculées en utilisant des données de température minimales à la température de conservation inférieures à $3^{\circ} \mathrm{C}$. Les sites présentant un risque supérieur à $50 \%$ et $60 \%$ d'occurrence de gel ont été séparés, c'est-à-dire que tous les 10 ans il y avait plus de cinq ou six ans avec au moins un gel en juillet. La région située entre le sud du Paraná et le nord de Rio Grande do Sul est celle qui présente le risque le plus élevé (supérieur à $50 \%$ ), en particulier dans les municipalités d'altitude, tandis que la région côtière et les vallées fluviales diminuent. fonction d'altitude plus basse et d'humidité plus élevée. Cependant, dans la moitié sud du Rio Grande do Sul, même à basse altitude, le risque de gel est élevé en raison de la latitude. Ce travail sert de base aux études de zonage agricole sur les risques climatiques, qui sont d'importants instruments de politique agricole pour l'octroi de l'assurance agricole et du crédit.

MOTS CLÉS: risques climatiques; zonage agricole; planification de l'utilisation des terres; politique agricole; distribution de Gumbel.

\section{INTRODUÇÃO}

As plantas têm diferentes níveis de tolerância à ocorrência de baixas temperaturas. O conhecimento sobre o nível de tolerância é essencial para os estudos dos riscos climáticos e de sua aplicação no Zoneamento Agrícola, principalmente nos estados do Centro-Sul do Brasil, onde o risco de geada é 
maior. Nesta região do país, a temperatura do ar tem forte variação espacial, principalmente nos estados do Paraná e de São Paulo, situados na faixa de transição climática do trópico de Capricórnio e cuja altitude varia entre 0 e 2785 $\mathrm{m}$.

No Brasil, as geadas são mais comuns no período entre abril e setembro, sendo mais críticas em junho e julho. Em algumas regiões, os riscos são baixos, principalmente nas regiões norte e oeste de São Paulo, norte e noroeste do Paraná, no Alto Vale do Uruguai e zonas costeiras (ZAICOVSKI et al., 2008). As geadas no Brasil ocorrem com maior frequência nas latitudes ao sul do paralelo $19^{\circ}$ S nos estados de São Paulo, Mato Grosso do Sul, Minas Gerais, Paraná, Santa Catarina e Rio Grande do Sul (SOUZA et al., 2011). A ocorrência de geadas está associada à definição de zonas climáticas, separando os ecossistemas tropical e temperado e determinando a distribuição e a diversidade de espécies (ALVARES et al., 2017).

A temperatura mínima é uma variável climática de extrema importância para a agricultura, pois está associada às geadas, ondas de frio, horas ou unidades de frio e ao termoperíodo (BERLATO; ALTHAUS, 2010). Na região Centro-Sul do Brasil, a temperatura diminui nos meses de maio a setembro, com sucessivas e intensas entradas de frentes frias vindas do sul e que trazem, geralmente, precipitações pluviais abundantes, seguidas por massas de ar frio. A entrada dessas massas é acompanhada de forte queda de temperatura, podendo chegar a valores próximos a $0^{\circ} \mathrm{C}$ e, não raramente, chegam a temperaturas negativas, proporcionando condições favoráveis à ocorrência de geada (NIMER, 1979).

A temperatura mínima do ar, medida no abrigo meteorológico a aproximadamente $1,5 \mathrm{~m}$ de altura em relação ao nível do solo, tem forte relação com a ocorrência de geada. Essa relação foi medida e analisada no estado do Paraná por GRODZKI et al. (1996). Outros autores também relacionaram as temperaturas medidas no abrigo menores que 2 ou $3^{\circ} \mathrm{C}$ com ocorrência de geada (CARAMORI et al., 1999; 2000; PINTO et al., 2001; WREGE et al., 2004; BERLATO; ALTHAUS, 2010). Entre a altura de medição da temperatura mínima e a relva ocorre um gradiente de temperatura superior a $3^{\circ} \mathrm{C}$, devido à inversão térmica que ocorre em noites frias e sem vento (SILVA e SENTELHAS, 2001). Assim, quando os sensores de temperatura registram entre 2 e $4^{\circ} \mathrm{C}$ no abrigo meteorológico, a temperatura na relva é de aproximadamente $0^{\circ} \mathrm{C}$, ocasionando a geada.

As temperaturas baixas são comuns no sul do Brasil, podendo chegar até a $-12{ }^{\circ} \mathrm{C}$ (média da temperatura mínima absoluta em julho), nos municípios de maior altitude de Santa Catarina e do Rio Grande do Sul (WREGE et al., 2011). No inverno de 2013, foi observada até mesmo precipitação de pequena quantidade de chuva congelada no sul do Brasil e a temperatura mínima chegou a $-8{ }^{\circ} \mathrm{C}$ em alguns locais, causando perdas para as culturas do trigo, milho safrinha, feijão, pastos, florestas, entre outras (ALVARES et al., 2017).

A caracterização dos riscos climáticos é necessária para o Zoneamento Agrícola de Riscos Climáticos (ZARC), instrumento básico de política agrícola para fins de concessão de seguro rural e crédito agrícola. A indicação de regiões e épocas para plantio comercial de espécies agrícolas é baseada nos riscos climáticos e, no sul do país, o risco de geada é o mais importante deles. Para o ZARC, o Ministério da Agricultura, Pecuária e Abastecimento (MAPA), considera 
como sendo aceitos os riscos de até $20 \%$, como é o caso do Zoneamento Agrícola do Café (PINTO et al., 2001). Esse percentual foi estabelecido, considerando como sendo aceitável ocorrer 1 perda de safra a cada 5 anos. Essa regra foi definida pela Comissão Especial de Recursos (CER), do "Programa de Garantia da Atividade Agropecuária - PROAGRO" e é um parâmetro utilizado pelo programa para indenizar o produtor em caso de perda ou queda de safra em um ano em que o risco for maior que o aceitável. Esse valor tem sido revisto e, atualmente, estão sendo aceitos riscos maiores.

As atividades florestais também são afetadas pela ocorrência de geada na região Centro-Sul do país. Nas últimas décadas, vários eventos de geada foram associados a danos causados aos plantios comerciais de eucalipto (FERREIRA, 2015;GARCIA e SANTOS, 1995). Adicionalmente, os eventos de geada estão associados à ocorrência de incêndios florestais (ALVARES et al., 2017).

O objetivo do presente trabalho foi caracterizar, espacializar e estabelecer escalas de risco de ocorrência de geada nos estados da região Centro-Sul do Brasil (estados de São Paulo, do Paraná, de Santa Catarina e do Rio Grande do Sul), por meio da aplicação do modelo de "distribuição de valores extremos" (Gumbel) e correlacioná-los às variáveis altitude, latitude e longitude de cada estado, utilizando análise multivariada.

\section{MATERIAL E MÉTODOS}

Base de dados climáticos usada para o cálculo do risco de geada

Foi utilizada uma rede de 80 estações meteorológicas (Figura 1), cujos dados foram analisados, verificando sua consistência e completude e corrigindo os erros existentes, sempre que possível, buscando-se usar o mesmo período de referência (anos) para todas as estações meteorológicas. 


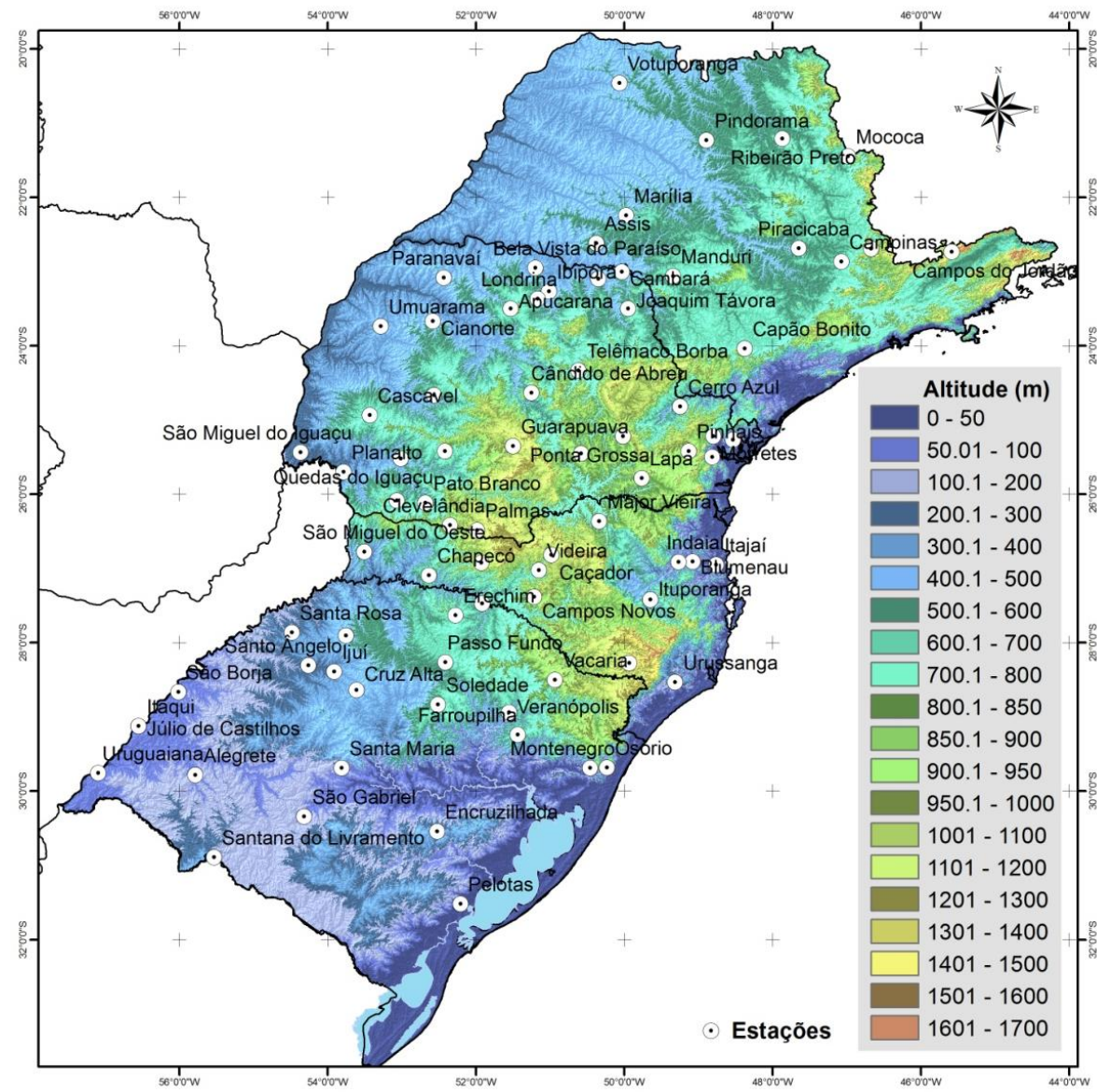

Figura 1 - Localização das estações meteorológicas e mapa de altitude (m).

O risco de ocorrência de geada foi calculado utilizando a série temporal de dados climáticos fornecidos pelos institutos estaduais de pesquisa de São Paulo, do Paraná, de Santa Catarina e do Rio Grande do Sul (IAC, IAPAR, Epagri e Fepagro), analisando o período-base 1976-2005. No caso do IAC, utilizou-se o período entre 1990 e 2015, em função da disponibilidade de dados.

\section{CÁlCulo do Risco de geada pela "Distribuição de VAlores EXTREMOS"}

Para o cálculo da "distribuição de valores extremos", conhecida também como "distribuição de Gumbel", utilizou-se a série de dados com temperaturas mínimas absolutas mensais da rede de 80 estações meteorológicas mencionada anteriormente.

Segundo CAMARGO et al. (1993), citando THOM (1966), a função de densidade de probabilidade de distribuição de valores extremos é dada por:

Equação 1

$$
\mathrm{f}(\mathrm{x})=\left(\frac{1}{\beta}\right) \exp \left[-\left(\frac{(\mathrm{x}-\alpha)}{\beta}\right)-\exp ^{-\left(-\frac{\mathrm{x}-\alpha}{\beta}\right)}\right]-\infty<\alpha<\infty
$$


Em que: $\alpha$ e $\beta$ são parâmetros da distribuição. valor x é:

A probabilidade $(P)$ de que a temperatura mínima $(T)$ seja inferior a um

\section{Equação 2}

$$
\mathrm{P}(\mathrm{T} \leq \mathrm{x})=\beta \int_{-\infty}^{1} \exp \left[-\left(\frac{x-\alpha}{\beta}\right)-\exp ^{\left[\exp \left(-\frac{\mathrm{x}-\alpha}{\beta}\right)\right.}\right] \mathrm{dy}
$$

Assim, desenvolvendo a Equação 2, tem-se a seguinte equação simplificada (Equação 3):

\section{Equação 3}

$$
P(T \leq x)=\exp ^{\left[-\exp -\left(-\frac{\mathrm{x}-\alpha}{\beta}\right)\right]}
$$

$\alpha$ e $\beta$ foram estimados pelo método de "Lieblein" (THOM, 1966), baseado nas variâncias mínimas, na qual dividiu-se a série de dados climáticos em subgrupos. Cada subgrupo foi ordenado na ordem crescente e, posteriormente, reagrupado, unindo os menores valores em um novo subgrupo, e assim por diante, até unir os maiores valores em um último subgrupo. A somatória de cada subgrupo foi multiplicada pelos valores $a_{j}$ e $b_{j}$ (valores tabelados) para 0 cálculo do $\alpha$ e $\beta$ (ASTOLPHO, 2003). Os cálculos probabilísticos foram feitos para a temperatura mínima de $3{ }^{\circ} \mathrm{C}$.

Utilizou-se o método de Kolmogorov-Smirnov a 5\% de probabilidade para analisar o ajuste entre as frequências das temperaturas mínimas absolutas e as estimadas pelo método da "distribuição de valores extremos", sugerido por CAMARGO et al. (1993).

\section{MAPEAMENTO DO RISCO DE GEADA}

Para a elaboração dos mapas de risco de geada, referentes a cada estado, foram empregadas regressões lineares múltiplas elaboradas com os dados de risco de geada em função da altitude (MNT - modelo numérico do terreno), da latitude e da longitude, de acordo com a metodologia de PINTO et al. (1972) (Tabela 1). Os riscos foram calculados com os dados organizados e compilados por WREGE et al (2011) e foi incluído o estado de São Paulo. Foram feitos dois conjuntos de regressões, um para a região sul, usando dados dos três estados do sul (dados de 73 estações meteorológicas), e outro para o estado de São Paulo, usando dados de São Paulo e do Paraná (dados de 46 estações meteorológicas). 
Tabela 1 - Coeficientes das equações de regressão lineares múltiplas do risco de ocorrência de geada para os estados de São Paulo, Paraná, Santa Catarina e Rio Grande do Sul (ver equação abaixo) nos meses de maio a setembro.

\begin{tabular}{|c|c|c|c|c|c|}
\hline \multirow{2}{*}{ Estados do sul } & \multicolumn{5}{|c|}{ Coeficientes da equação de regressão } \\
\hline & $\alpha$ & $\beta$ & $\chi$ & $\delta$ & $r^{2}$ \\
\hline Maio & $-2,558628$ & $-0,098275$ & $-0,001297$ & 0,000554 & 0,805 \\
\hline Junho & $-3,224801$ & $-0,113316$ & $-0,009141$ & 0,000546 & 0,800 \\
\hline Julho & $-1,954851$ & $-0,099093$ & 0,008907 & 0,000554 & 0,715 \\
\hline Agosto & $-1,982653$ & $-0,107578$ & 0,015524 & 0,000510 & 0,643 \\
\hline Setembro & $-0,251886$ & $-0,057161$ & 0,025877 & 0,000407 & 0,414 \\
\hline \multirow{2}{*}{ Estado de $\mathrm{SP}^{(1)}$} & \multicolumn{5}{|c|}{ Coeficientes da equação de regressão } \\
\hline & $\alpha$ & $\beta$ & $\chi$ & $\delta$ & $r^{2}$ \\
\hline Maio & $-1,963312$ & $-0,096962$ & 0,010128 & 0,000568 & 0,816 \\
\hline Junho & $-2,449845$ & $-0,114194$ & 0,006677 & 0,000556 & 0,796 \\
\hline Julho & $-2,136187$ & $-0,102240$ & 0,007990 & 0,000601 & 0,796 \\
\hline Agosto & $-0,396587$ & $-0,057264$ & 0,021677 & 0,000390 & 0,673 \\
\hline
\end{tabular}

\section{Equação 4}

Equação de regressão:

Mapa do risco de geada $(\%)=\propto+\beta$ x latitude $+\gamma x$ longitude $+\delta x M N T *$

(ver Tabela 1)

(1)Não foi apresentada a equação de regressão de geada em setembro para o estado de São Paulo, pois na maior parte do estado o risco é "zero".

* latitude, longitude e MNT são as variáveis independentes da equação, na forma de mapas da região em formato "raster".

Foi utilizado o Modelo Numérico do Terreno (MNT) do GTOPO30, o qual reproduz as cotas altimétricas do Brasil, elaborado pelo Serviço Geológico dos Estados Unidos - "United States Geological Survey" (USGS, 2011), a partir de imagens de radar, o qual corresponde a uma "grade" hipsométrica uniforme, com valores de altitude a cada 90 metros. Foram elaborados, ainda, modelos dos paralelos e dos meridianos, os quais reproduzem a latitude e a longitude do Brasil, também com valores a cada 90 metros, na escala 1:250.000, assim como o MNT.

Assim, foram criados os três mapas básicos, correspondendo às variáveis independentes da equação de regressão, com os modelos numéricos ("grades") necessários para a construção do mapa de risco de geada (variável dependente da equação). A equação foi usada na função calculadora de mapas ("raster calculator") do programa ArcGIS 10.

As figuras foram geradas formando uma "grade" com valores de risco de geada a cada 90 metros nos quatro estados, na escala 1:250.000.

Foram utilizados ainda mapas dos limites municipais, divisas estaduais e fronteira federal do IBGE (2001), mapas oficiais do Brasil, para fazer os recortes dos mapas de risco de geada para cada estado.

Os mapas foram classificados delimitando as zonas pelo risco de geada, com intervalos a cada $10 \%$ de risco, variando de 0 a $100 \%$, onde 0 representa a 
não ocorrência de geada e 100\%, o máximo risco de ocorrência de geada, isto é, em todos os anos ocorrem geadas nos meses de maio, junho, julho, agosto ou setembro.

\section{ANÁLISE MULTIVARIADA}

Com o objetivo de verificar em quais municípios o risco de geada é maior, foi feita uma análise separando os municípios com risco de ocorrência de geada maior que 60\% (SANSIGOLO e NERY, 2000) nos estados do Paraná (51 municípios), Santa Catarina (136 municípios), Rio Grande do Sul (269 municípios) e São Paulo (20 municípios), o que corresponde àqueles em que havia 6 ou mais anos, em um total de 10 anos, com pelo menos 1 geada no mês de julho.

Após este procedimento, foram obtidas as correlações (de Pearson) entre o risco de geada e a altitude, a latitude e a longitude para todos os estados. Foi testada a normalidade dos dados e foram aplicados os testes de Kruskal Wallis para altitude (metros), risco de geada (\%), latitude e longitude (graus), com o objetivo de verificar se havia diferença nestes parâmetros para os estados do Paraná, Santa Catarina e Rio Grande do Sul. O estado de São Paulo não foi considerado devido à menor representação de estações com risco maior que $60 \%$. As diferenças, quando existentes, puderam ser observadas nas figuras do tipo Box Plot ("Box \& Whisker Plot").

Também foi efetuado o teste de Kolmogorov-Smirnov, que compara a distribuição entre amostras. Este teste é feito computando a máxima distância entre a distribuição cumulativa de duas amostras e, quando o valor $p$ resultante é menor que 0,05, há diferença significativa entre as duas distribuições a um nível de $95 \%$ de nível de confiança.

\section{RESULTADOS}

Os riscos de ocorrência de geada em maio, junho, julho, agosto e setembro para os estados de São Paulo, do Paraná, de Santa Catarina e do Rio Grande do Sul são apresentados nas Figuras 2 a 5 . Os dados não apresentaram distribuição normal e, por isso, foi testada a hipótese de igualdade das medianas, utilizando o teste não paramétrico de Kruskal Wallis. A Tabela 2 apresenta o teste de correlação de Pearson e a Tabela 3, o resultado do teste estatístico de Kruskal Wallis, com respectivo valor $\mathrm{p}$ para risco de ocorrência de geada, altitude, latitude e longitude. Foram apresentados também o valor mínimo, médio e máximo, o coeficientes de variação, o desvio padrão e a amplitude dos parâmetros estudados, além do teste de Kolmogorov-Smirnov. Os resultados foram apresentados nos gráficos do tipo Box Plot (Figuras 6 a 9).

O modelo de "distribuição de extremos" possibilitou um bom ajuste entre frequências estimadas e observados de ocorrência de temperaturas mínimas absolutas menores que $3^{\circ} \mathrm{C}$, valor de referência relacionado à ocorrência de geada (GRODZKI et al., 1996).

As análises foram feitas para os meses de maio a setembro nos estados do Paraná, de Santa Catarina e do Rio Grande do Sul e, maio a agosto, no estado de São Paulo, devido à entrada de mais frentes frias de origem polar nessa 
época do ano, de ocorrer redução de absorção de ondas longas e curtas devido ao baixo nível de vapor de água na atmosfera e noites mais longas e de céu limpo, o que favorece a perda de calor para a atmosfera e a queda da temperatura do ar (CAMARGO et al., 1993).

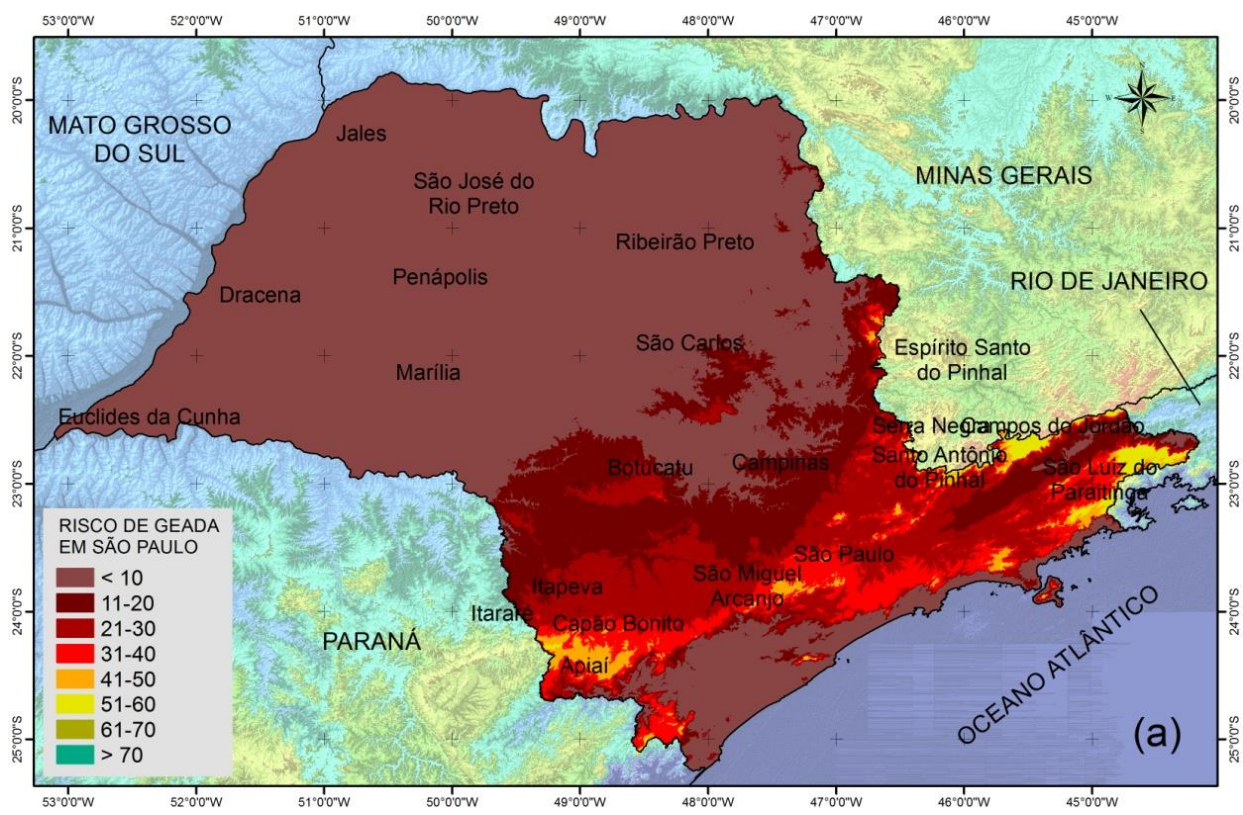

Figura 2a - Risco de ocorrência de geada no estado de São Paulo no mês de maio (a).

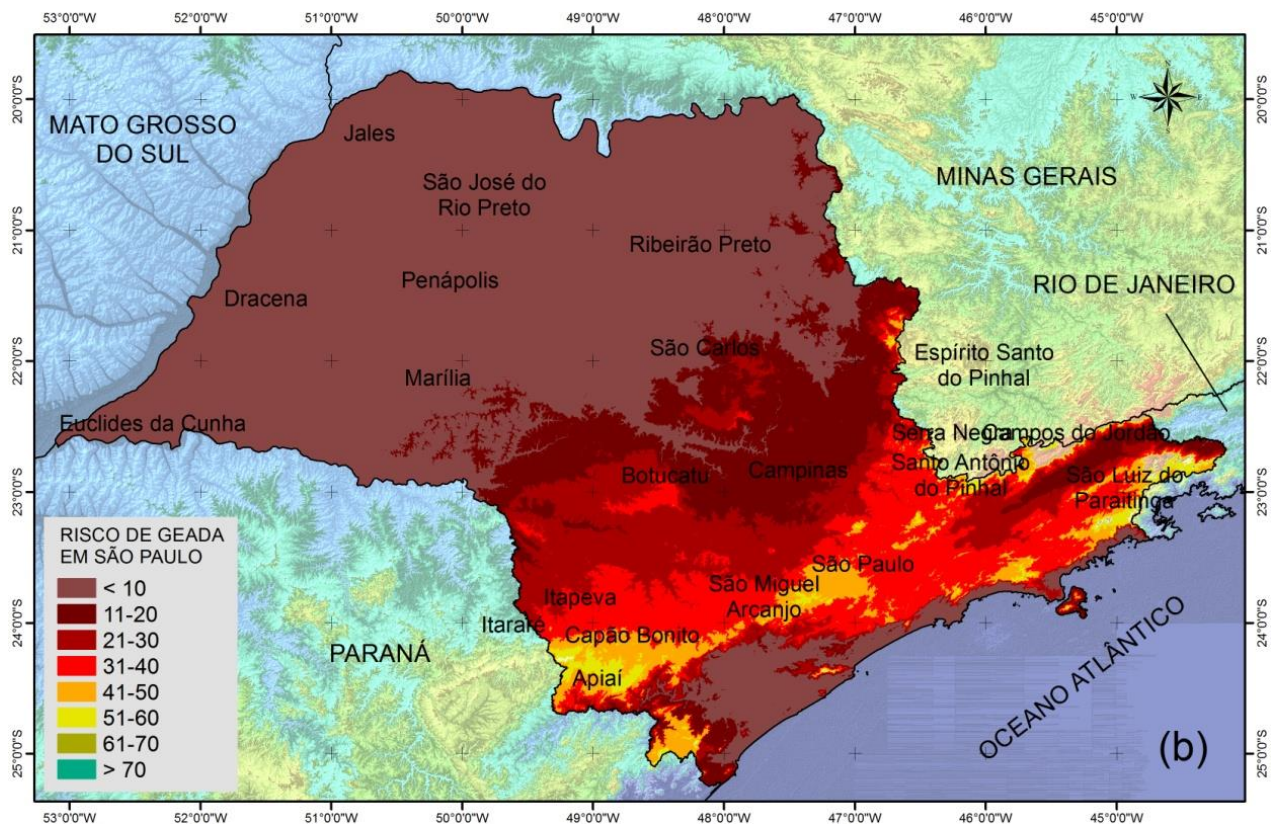

Figura 2b - Risco de ocorrência de geada no estado de São Paulo no mês de junho (b). 
Tabela 2 - Correlação de Pearson entre o risco de geada (\%), altitude, latitude e longitude para os estados de São Paulo, Paraná, Santa Catarina e Rio Grande do Sul.

\begin{tabular}{|c|c|c|c|c|c|c|c|}
\hline \multirow[t]{2}{*}{ Estados } & \multicolumn{3}{|c|}{ altitude } & \multirow{2}{*}{$\begin{array}{l}\text { latitude } \\
\mathrm{R}\end{array}$} & \multicolumn{3}{|c|}{ longitude } \\
\hline & $\mathrm{N}$ & $\mathrm{R}$ & valor $p$ & & valor $p$ & $\mathrm{R}$ & valor $p$ \\
\hline Todos os estados & 477 & 0,44 & $0,000 *$ & 0,11 & 0,013 & 0,06 & 0,156 \\
\hline São Paulo & 20 & 0,92 & $0,000 *$ & $-0,65$ & $0,002 *$ & $-0,39$ & 0,092 \\
\hline Paraná & 52 & 0,43 & $0,002 *$ & 0,14 & 0,332 & $-0,07$ & 0,583 \\
\hline Santa Catarina & 136 & 0,68 & $0,000 *$ & $-0,18$ & 0,039 & 0,23 & $0,007 *$ \\
\hline Rio Grande do Sul & 269 & 0,49 & $0,000 *$ & 0,12 & 0,051 & $-0,15$ & $0,014^{*}$ \\
\hline
\end{tabular}

Nota: * Valores p da correlação de Pearson que ficaram abaixo de 0,05 , o que indica que os valores de correlação encontrados são significativamente diferentes de 0 a um nível de confiança de 95\%; N é o número de amostras (municípios com risco de geada maior que $60 \%$ ); R é o valor da correlação.

Tabela 3 - Teste estatístico de Kruskal Wallis com valor p para risco de geada, altitude e longitude, valores médios, mínimos e máximos, coeficiente de variação (CV), desvio padrão (DP) e amplitude e teste de Kolmogorov-Smirnov, com valor DN, K-S e p.

\begin{tabular}{|c|c|c|c|c|c|c|c|c|c|c|c|c|}
\hline $\begin{array}{l}\text { Estados / } \\
\text { parâmetros }\end{array}$ & $\begin{array}{l}\text { Teste } \\
\text { Estatístico* }\end{array}$ & $p$ & média & $\begin{array}{l}\text { valor } \\
\text { máximo }\end{array}$ & $\begin{array}{l}\text { valor } \\
\text { mínimo }\end{array}$ & $\mathrm{CV}$ & $\mathrm{DP}$ & amplitude & $\begin{array}{l}\text { Teste } \\
\text { Estatístico** } \\
\text { Estados }\end{array}$ & DN & $\mathrm{K}-\mathrm{S}$ & $\mathrm{p}$ \\
\hline \multicolumn{13}{|l|}{ Altitude (m) } \\
\hline Paraná & 114,61 & $0^{*}$ & 1029 & 1208 & 650 & 11,39 & 104,6 & 558 & PR e SC & 0,515837 & 3,1638 & $0^{*}$ \\
\hline Santa Catarina & & & 599 & 1376 & 2 & 65,16 & 390,8 & 1374 & PR e RS & 0,87167 & 5,7541 & $0^{*}$ \\
\hline Rio Grande do Sul & & & 417 & 1187 & 1 & 73,36 & 306,0 & 1186 & SC e RS & 0,377405 & 3,5869 & $0^{*}$ \\
\hline \multicolumn{13}{|l|}{$\begin{array}{l}\text { Risco de geada } \\
(\%)\end{array}$} \\
\hline Paraná & 4,427 & 0,109 & 63,3 & 82,75 & 59,5 & 6,61 & 4,31 & 23,25 & PR e SC & 0,298077 & 1,8281 & $0,0025^{*}$ \\
\hline Santa Catarina & & & 82 & 100 & 69,3 & 14,95 & 10,36 & 40,9 & PR e RS & 0,29789 & 1,9665 & $0,0009^{*}$ \\
\hline Rio Grande do Sul & & & 68,22 & 98,38 & 59,5 & 11,02 & 7,52 & 38,9 & SC e RS & 0,13782 & 1,3099 & 0,0646 \\
\hline \multicolumn{13}{|c|}{$\begin{array}{l}\text { Longitude } \\
\text { (graus decimais) }\end{array}$} \\
\hline $\begin{array}{l}\text { Paraná } \\
\text { Santa Catarina }\end{array}$ & 192,63 & $0^{*}$ & $\begin{array}{l}-50,13 \\
-50,22\end{array}$ & $\begin{array}{l}-49,05 \\
-48,67\end{array}$ & $\begin{array}{l}-53,06 \\
-53,50\end{array}$ & $\begin{array}{l}-2,06 \\
-1,89\end{array}$ & $\begin{array}{l}1,034 \\
0.951\end{array}$ & $\begin{array}{l}4,01 \\
4.83\end{array}$ & $\begin{array}{l}\text { PR e SC } \\
\text { PR e RS }\end{array}$ & $\begin{array}{l}0,1431 \\
0.63540\end{array}$ & $\begin{array}{l}0,8766 \\
4,1944\end{array}$ & $\begin{array}{l}0,430 \\
0^{*}\end{array}$ \\
\hline
\end{tabular}




\begin{tabular}{|c|c|c|c|c|c|c|c|c|c|c|c|}
\hline Rio Grande do Sul & & $-51,86$ & $-49,72$ & $-57,09$ & $-2,05$ & 1,065 & 7,36 & SC e RS & 0,59725 & 5,6764 & $0^{*}$ \\
\hline \multicolumn{12}{|l|}{$\begin{array}{l}\text { Latitude } \\
\text { (araus decimais) }\end{array}$} \\
\hline $\begin{array}{ll}\text { Paraná } & 128,38\end{array}$ & $0^{*}$ & $-25,63$ & $-24,33$ & $-26,48$ & $-1,73$ & 0,444 & 2,15 & PR e SC & 0,89366 & \multirow{2}{*}{\multicolumn{2}{|c|}{$\begin{array}{ll}5,48109 & 0 \\
6,60124 & 0\end{array}$}} \\
\hline Santa Catarina & & $-27,59$ & $-26,11$ & $-29,31$ & $-3,04$ & 0,839 & 3,21 & PR e RS & 1,0 & & \\
\hline Rio Grande do Sul & & $-29,34$ & $-27,39$ & $-33,69$ & $-3,88$ & 1,140 & 6,30 & SC e RS & 0,58883 & 5,59645 & $0^{*}$ \\
\hline
\end{tabular}

Nota: * testes de Kruskal Wallis; ** teste de Kolmogorov-Smirnov (DN é o resultado do teste estatístico e K-S é a estimativa); valor p* (menor que 0,05) denota diferença significativa a um nível de 95,0\% de nível de confiança.

Tabela 4 - Valores de $\alpha$ e $\beta$ calculados pelo modelo de "distribuição de valores extremos" nos estados de São Paulo (SP), do Paraná (PR), de Santa Catarina (SC) e do Rio Grande do Sul (RS) nos meses de maio a setembro.

\begin{tabular}{|c|c|c|c|c|c|c|c|c|c|c|c|}
\hline \multirow[t]{2}{*}{ Estado } & \multirow[t]{2}{*}{ Município } & \multicolumn{2}{|c|}{ maio } & \multicolumn{2}{|c|}{ junho } & \multicolumn{2}{|c|}{ julho } & \multicolumn{2}{|c|}{ agosto } & \multicolumn{2}{|c|}{ setembro } \\
\hline & & $\alpha$ & $\beta$ & $\alpha$ & $\beta$ & $\alpha$ & $\beta$ & $\alpha$ & $\beta$ & $\alpha$ & $\beta$ \\
\hline \multirow{7}{*}{ SP } & Campinas & 31,05 & 10,39 & 24,66 & 12,46 & 23,35 & 10,19 & 30,32 & 10,97 & 40,07 & 8,58 \\
\hline & Capão Bonito & 18,56 & 10,12 & 9,72 & 10,58 & 9,69 & 10,76 & 15,07 & 12,43 & 24,98 & 9,54 \\
\hline & Manduri & 13,87 & 9,93 & 5,46 & 12,25 & 6,26 & 9,53 & 10,22 & 10,33 & 22,97 & 11,48 \\
\hline & Marília & 31,22 & 10,87 & 21,78 & 14,63 & 20,32 & 13,58 & 25,16 & 13,06 & 32,70 & 12,73 \\
\hline & Mococa & 27,26 & 9,77 & 21,91 & 11,12 & 19,85 & 11,59 & 26,36 & 10,36 & 35,79 & 11,22 \\
\hline & Piracicaba & 22,89 & 7,43 & 12,39 & 11,28 & 14,15 & 8,02 & 16,35 & 9,22 & 27,65 & 9,59 \\
\hline & Ribeirão Preto & 32,52 & 5,11 & 23,56 & 12,11 & 23,08 & 13,25 & 27,98 & 9,52 & 37,24 & 11,29 \\
\hline \multirow[t]{4}{*}{ PR } & Antonina & 29,36 & 12,80 & 17,77 & 10,53 & 18,31 & 9,14 & 17,80 & 10,80 & 32,87 & 7,92 \\
\hline & Apucarana & 37,45 & 18,00 & 22,99 & 15,45 & 16,40 & 21,88 & 25,72 & 18,65 & 44,95 & 12,58 \\
\hline & Bandeirantes & 30,08 & 12,63 & 18,00 & 15,19 & 18,89 & 16,13 & 28,44 & 12,99 & 44,80 & 10,56 \\
\hline & Bela Vista do Paraíso & 36,47 & 13,76 & 25,10 & 13,08 & 22,96 & 16,99 & 27,94 & 13,64 & 41,17 & 9,93 \\
\hline
\end{tabular}




\begin{tabular}{|c|c|c|c|c|c|c|c|c|c|c|c|}
\hline & Cerro Azul & 20,49 & 13,27 & 7,48 & 11,76 & 6,88 & 12,89 & 9,84 & 10,80 & 23,61 & 8,65 \\
\hline & Cianorte & 31,65 & 14,95 & 17,82 & 12,23 & 14,47 & 15,65 & 23,97 & 18,26 & 37,05 & 13,58 \\
\hline & Fernandes Pinheiro & 13,01 & 12,36 & $-5,71$ & 12,30 & $-6,86$ & 14,01 & 1,76 & 15,89 & 15,96 & 15,61 \\
\hline & Guarapuava & 3,29 & 13,44 & $-9,43$ & 12,87 & $-10,09$ & 12,79 & $-2,44$ & 15,48 & 6,82 & 12,63 \\
\hline & Guaraqueçaba & 28,57 & 14,75 & 18,87 & 12,37 & 16,80 & 10,37 & 18,84 & 11,55 & 33,45 & 9,37 \\
\hline & Ibiporã & 36,43 & 12,69 & 21,44 & 14,02 & 21,16 & 15,98 & 28,86 & 15,29 & 45,48 & 9,91 \\
\hline & Joaquim Távora & 23,45 & 14,08 & 9,18 & 13,62 & 8,98 & 17,24 & 19,71 & 14,71 & 38,29 & 10,91 \\
\hline & Londrina & 28,89 & 11,74 & 15,63 & 12,71 & 16,02 & 14,89 & 20,18 & 15,58 & 37,06 & 11,35 \\
\hline & Morretes & 48,63 & 16,54 & 33,31 & 11,16 & 28,42 & 14,31 & 31,83 & 17,10 & 46,96 & 14,58 \\
\hline & Nova Cantu & 21,47 & 12,22 & 5,99 & 11,16 & 6,59 & 12,34 & 13,70 & 14,90 & 26,12 & 14,61 \\
\hline & Palmas & $-0,17$ & 8,09 & $-8,37$ & 9,65 & $-11,50$ & 9,38 & $-6,07$ & 11,10 & 1,42 & 8,92 \\
\hline & Palotina & 14,24 & 12,92 & 0,68 & 12,51 & $-3,72$ & 11,89 & 3,11 & 14,41 & 18,72 & 13,98 \\
\hline & Paranavaí & 33,07 & 11,91 & 20,42 & 12,90 & 15,84 & 16,10 & 23,19 & 18,61 & 38,18 & 13,69 \\
\hline & Quedas do Iguaçu & 17,44 & 9,79 & 6,24 & 8,20 & 6,25 & 8,03 & 9,00 & 10,21 & 20,48 & 9,11 \\
\hline & Telêmaco Borba & 9,57 & 12,80 & $-1,89$ & 10,98 & $-3,59$ & 12,73 & 3,22 & 11,63 & 14,22 & 10,94 \\
\hline & Umuarama & 32,11 & 12,81 & 20,88 & 11,20 & 16,20 & 13,32 & 24,90 & 16,23 & 36,92 & 13,91 \\
\hline SC & São Miguel do Oeste & 10,56 & 6,82 & 2,16 & 3,21 & 0,01 & 4,40 & 2,08 & 8,48 & 9,45 & 5,86 \\
\hline & Itajaí & 25,56 & 9,42 & 15,83 & 8,38 & 10,74 & 8,25 & 13,85 & 9,87 & 28,78 & 7,33 \\
\hline & Caçador & $-8,36$ & 9,09 & $-14,61$ & 8,90 & $-16,86$ & 6,92 & $-14,16$ & 8,77 & $-5,20$ & 7,91 \\
\hline & Videira & $-3,04$ & 8,94 & $-10,92$ & 8,55 & $-14,74$ & 7,60 & $-9,96$ & 9,11 & $-0,26$ & 7,58 \\
\hline & Campos Novos & 2,44 & 6,14 & $-5,35$ & 7,49 & $-8,82$ & 5,12 & $-5,14$ & 8,84 & 3,77 & 5,55 \\
\hline & Ponte Serrada & 1,28 & 8,08 & $-3,87$ & 7,24 & $-8,94$ & 6,42 & $-4,93$ & 9,88 & 0,92 & 8,07 \\
\hline & Major Vieira & $-4,11$ & 9,02 & $-9,43$ & 7,62 & $-10,22$ & 6,42 & $-9,52$ & 8,60 & 0,74 & 7,95 \\
\hline & Blumenau & 11,38 & 5,32 & 8,85 & 4,87 & 5,05 & 4,83 & 9,07 & 4,03 & 9,76 & 2,85 \\
\hline
\end{tabular}


Revista Brasileira de Climatologia

ISSN: 2237-8642 (Eletrônica)

\begin{tabular}{|c|c|c|c|c|c|c|c|c|c|c|c|}
\hline & $\begin{array}{l}\text { Indaial } \\
\text { Ituporanga }\end{array}$ & $\begin{array}{r}14,29 \\
5,12 \\
\end{array}$ & $\begin{array}{l}6,10 \\
7,62\end{array}$ & $\begin{array}{l}10,48 \\
-1,91 \\
\end{array}$ & $\begin{array}{l}8,02 \\
7,49 \\
\end{array}$ & $\begin{array}{r}7,02 \\
-5,38 \\
\end{array}$ & $\begin{array}{l}5,91 \\
5,82 \\
\end{array}$ & $\begin{array}{r}12,59 \\
0,19 \\
\end{array}$ & $\begin{array}{l}7,17 \\
7,64 \\
\end{array}$ & $\begin{array}{r}17,83 \\
8,69 \\
\end{array}$ & $\begin{array}{r}10,19 \\
7,70 \\
\end{array}$ \\
\hline \multirow{21}{*}{ RS } & Cachoeira & 7,92 & 7,56 & 2,54 & 3,97 & 3,82 & 5,77 & 8,71 & 6,02 & 9,41 & 3,24 \\
\hline & Cruz Alta & 3,67 & 6,25 & $-2,26$ & 5,66 & $-5,82$ & 9,02 & 0,67 & 5,67 & 1,39 & 5,83 \\
\hline & Encruzilhada & 9,69 & 9,79 & 0,59 & 6,75 & $-0,28$ & 5,66 & 3,74 & 6,11 & 5,63 & 7,44 \\
\hline & Erechim & 5,26 & 12,01 & $-3,62$ & 4,91 & $-5,62$ & 10,40 & 0,18 & 8,99 & 3,12 & 9,24 \\
\hline & Farroupilha & $-5,33$ & 8,80 & $-14,18$ & 7,08 & $-12,81$ & 7,02 & $-9,02$ & 7,76 & $-8,98$ & 7,16 \\
\hline & Itaqui & 1,44 & $-0,37$ & 0,09 & 1,21 & $-0,77$ & 1,43 & 1,59 & 1,09 & 2,15 & $-0,18$ \\
\hline & Júlio de Castilhos & 9,90 & 9,63 & $-0,73$ & 5,70 & 0,73 & 6,40 & 5,46 & 7,26 & 7,09 & 7,60 \\
\hline & Marcelino Ramos & 5,19 & $-0,69$ & 2,97 & $-1,28$ & 0,56 & 1,13 & 4,83 & $-2,28$ & 6,89 & $-3,63$ \\
\hline & Montenearo & 1,34 & 2.25 & $-0,16$ & $-0,34$ & 0,37 & 0.65 & 0.04 & $-0,07$ & 0.52 & 0,53 \\
\hline & Osório & 12,02 & 9,09 & 1,57 & 5,50 & $-0,84$ & 8,67 & 7,07 & 6,28 & 7,07 & 7,89 \\
\hline & Passo Fundo & 1,97 & 6,64 & $-3,39$ & 5,22 & $-3,65$ & 3,96 & 1,63 & 5,64 & 2,89 & 6,12 \\
\hline & Santa Rosa & 9,39 & $-1,61$ & 4,83 & $-0,24$ & 4,48 & 0,00 & 8,73 & $-0,98$ & 10,62 & $-1,83$ \\
\hline & Santo Augusto & 4,56 & 8,10 & $-4,10$ & 4,80 & $-4,24$ & 7,93 & 0,66 & 6,34 & 3,39 & 7,12 \\
\hline & São Borja & 10,39 & 9,89 & 1,42 & 7,91 & 1,77 & 6,62 & 6,57 & 5,35 & 11,24 & 7,11 \\
\hline & São Gabriel & 7,59 & 7,68 & $-0,75$ & 7,33 & 0,15 & 7,80 & 5,80 & 5,92 & 8,25 & 7,29 \\
\hline & São Valentim & 3,79 & $-0,62$ & 0,67 & $-2,85$ & $-0,01$ & 0,14 & 4,94 & $-3,27$ & 7,14 & $-4,00$ \\
\hline & Soledade & 4,66 & 5,96 & $-0,87$ & 3,25 & $-1,12$ & 3,76 & 3,59 & 6,88 & 3,40 & 4,29 \\
\hline & Taquari & 14,31 & 8,48 & 3,17 & 9,18 & 3,86 & 6,54 & 9,49 & 7,54 & 12,11 & 8,51 \\
\hline & Uruguaiana & 8,70 & 11,37 & $-2,97$ & 8,73 & $-1,63$ & 8,72 & 5,97 & 6,72 & 7,85 & 6,58 \\
\hline & Vacaria & $-14,06$ & 9,44 & $-21,87$ & 8,10 & $-19,14$ & 8,45 & $-14,34$ & 8,72 & $-11,49$ & 8,07 \\
\hline & Veranópolis & 2,47 & 9,89 & $-7,59$ & 7,83 & $-5,85$ & 8,14 & $-2,36$ & 8,12 & 2,07 & 8,06 \\
\hline
\end{tabular}


$\mathrm{Na}$ Tabela 4, são apresentados os valores de $\alpha$ e $\beta$ do modelo de "distribuição de valores extremos" para os meses de maio a setembro para os estados de São Paulo, do Paraná, de Santa Catarina e do Rio Grande do Sul. Pode-se, por estes parâmetros, estimar as probabilidades de ocorrência de temperaturas mínimas absolutas menores que qualquer valor pela Equação 3.

Pelo teste de Kolmogorov-Smirnov, não houve diferença estatística significativa ao nível de $5 \%$ de probabilidade entre os valores observados (probabilidade empírica) e os estimados (modelo de "distribuição de valores extremos") nos meses de junho a setembro (Tabela 5). No entanto, houve diferença para o mês de maio, em função do menor número de ocorrência de geadas, o que pode ter prejudicado a estimativa feita pelo modelo. Assim, os mapas (Figuras 2 a 5) foram feitos utilizando a probabilidade empírica, pois apesar de não ser significativo, o mês de maio é importante pelo fato de estar relacionado às geadas precoces (primeiras geadas de outono-inverno).

Tabela 5 - Teste comparativo da probabilidade empírica e da estimada pelo método da "distribuição de valores extremos" por Kolmogorov-Smirnov ao nível de $5 \%$ de probabilidade para os meses de maio a setembro.

\begin{tabular}{llllll}
\hline Parâmetros/meses & Maio & Junho* & Julho* & Agosto* & Setembro* \\
\hline DN & 0,4 & 0,2 & 0,128571 & 0,114286 & 0,228571 \\
K-S & 2,36643 & 1,18322 & 0,760639 & 0,676123 & 1,35225 \\
Valor p & 0,0000273 & 0,121634 & 0,609289 & 0,750526 & 0,0516127 \\
\hline
\end{tabular}

*Não significativo ao nível de $5 \%$ de probabilidade.

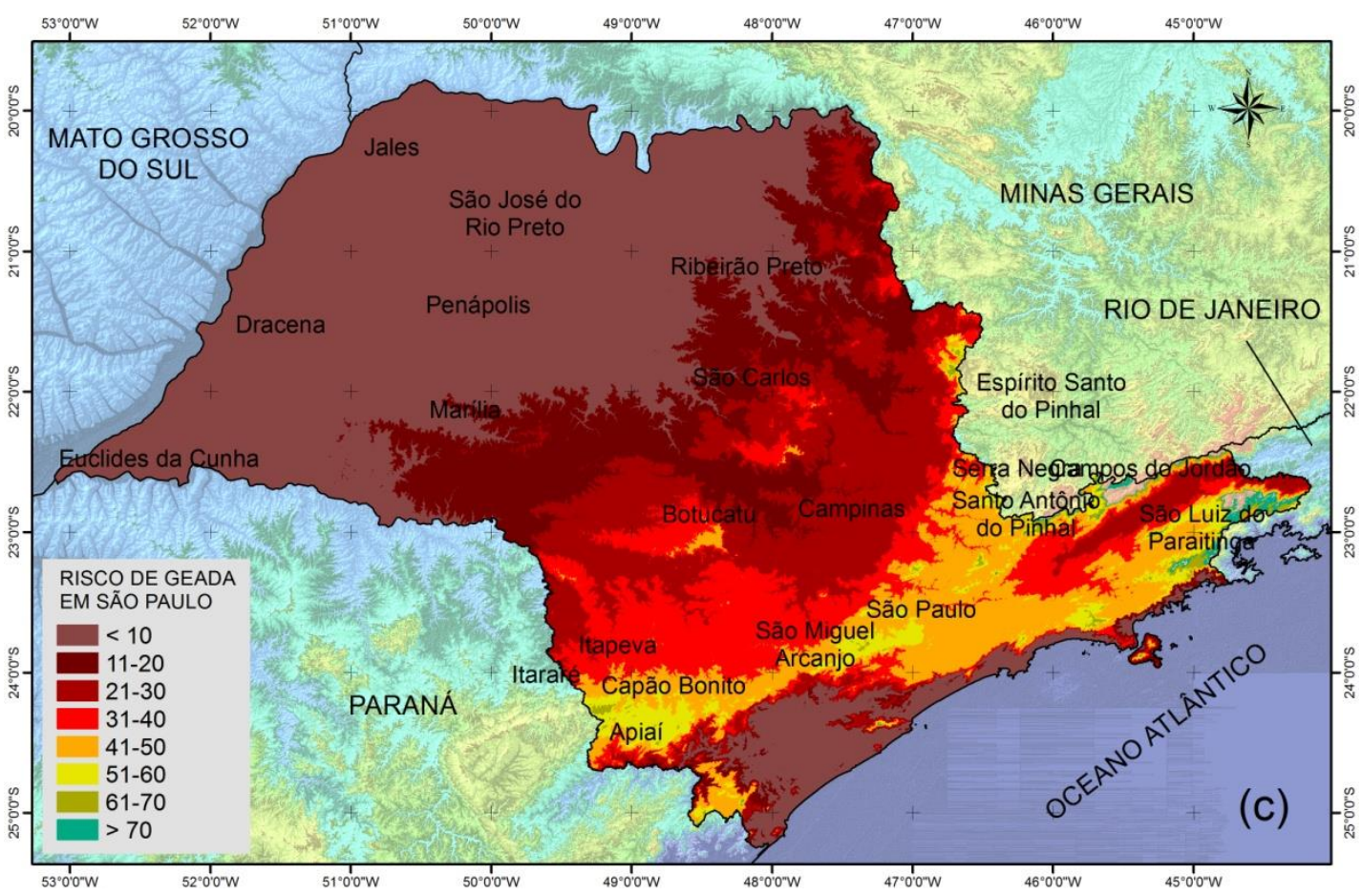

Figura 2c - Risco de ocorrência de geada no estado de São Paulo no mês de julho (c). 


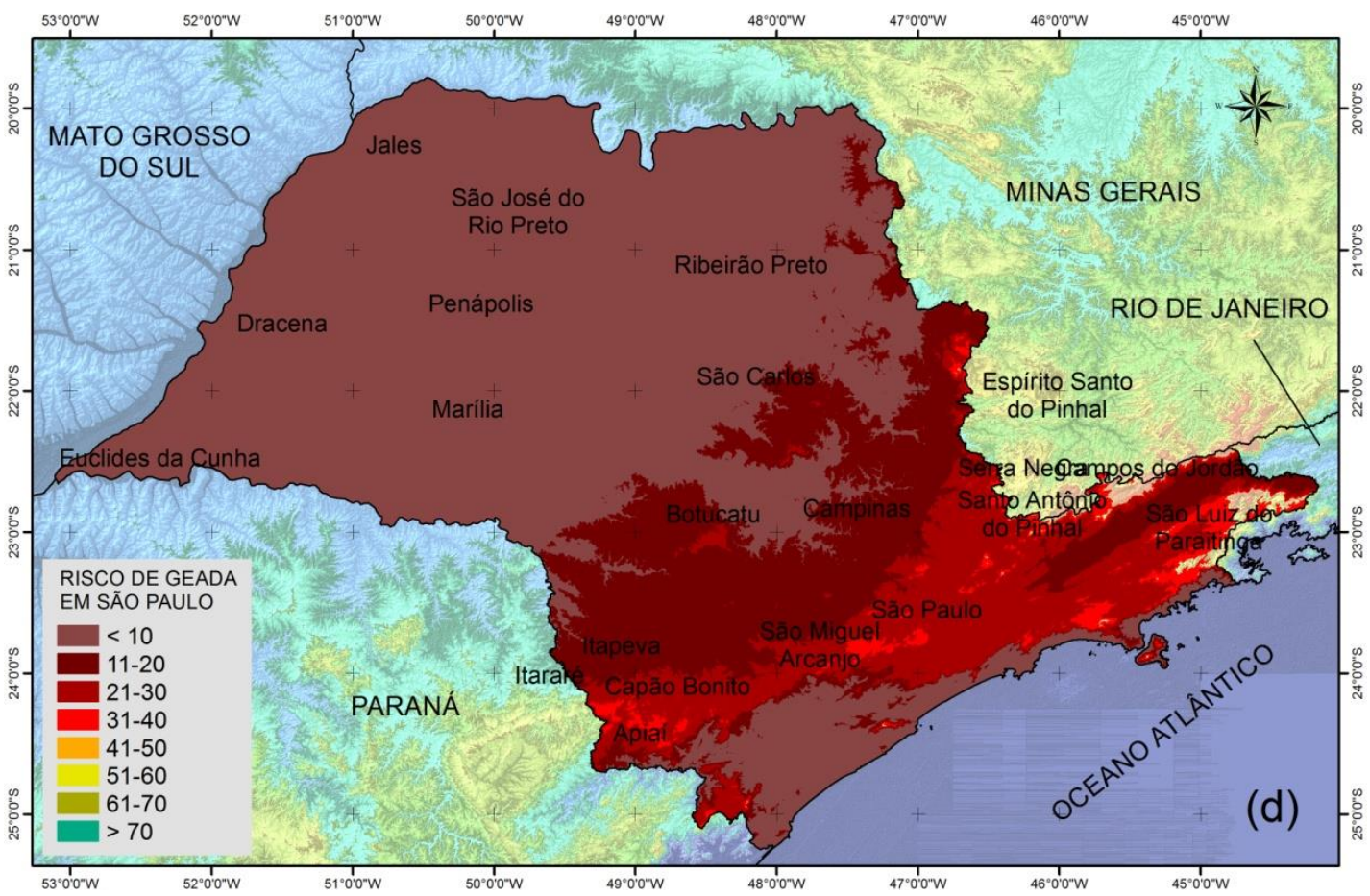

Figura 2d - Risco de ocorrência de geada no estado de São Paulo no mês de agosto (d).

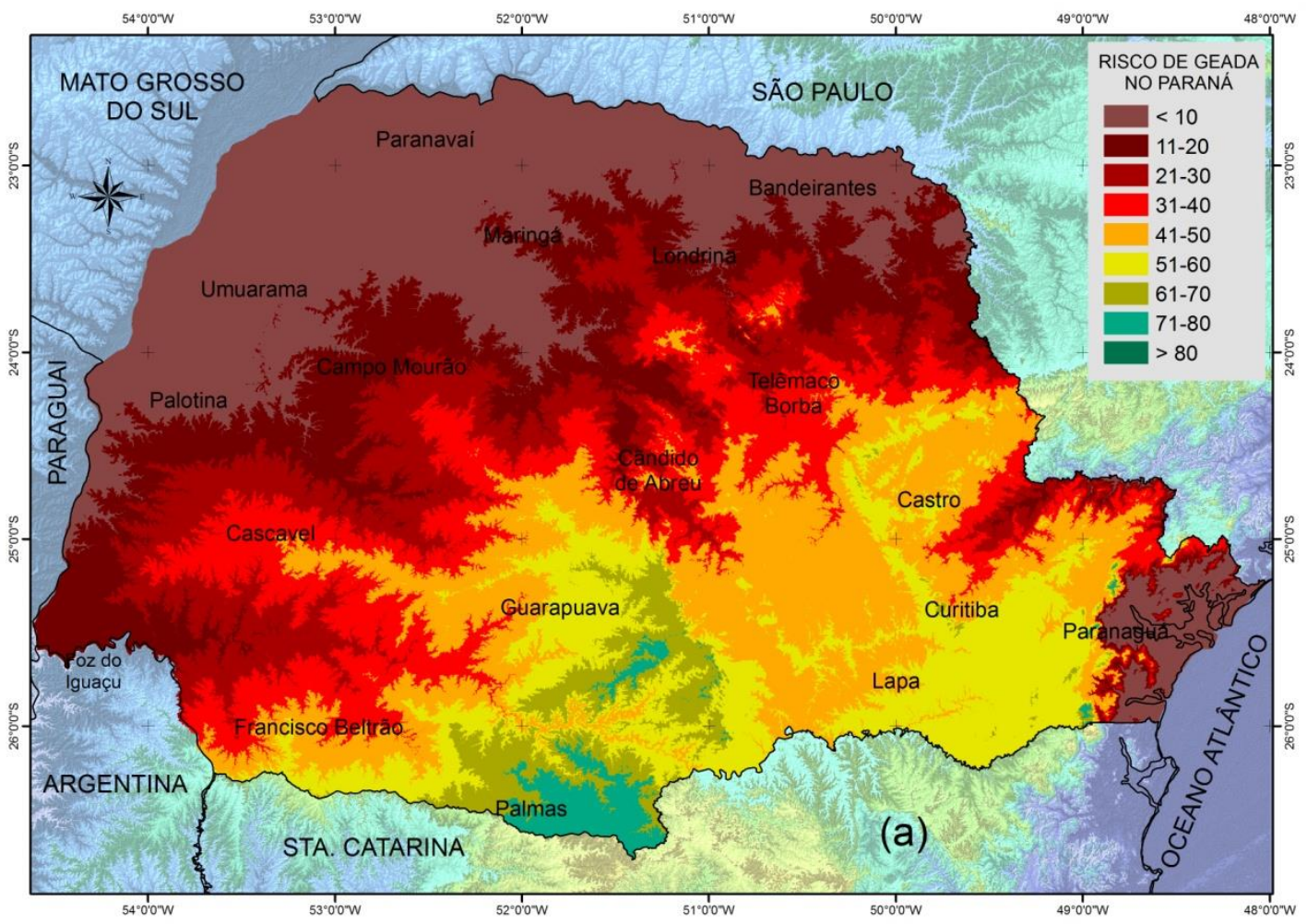

Figura 3a - Risco de ocorrência de geada no estado do Paraná no mês de maio (a). 


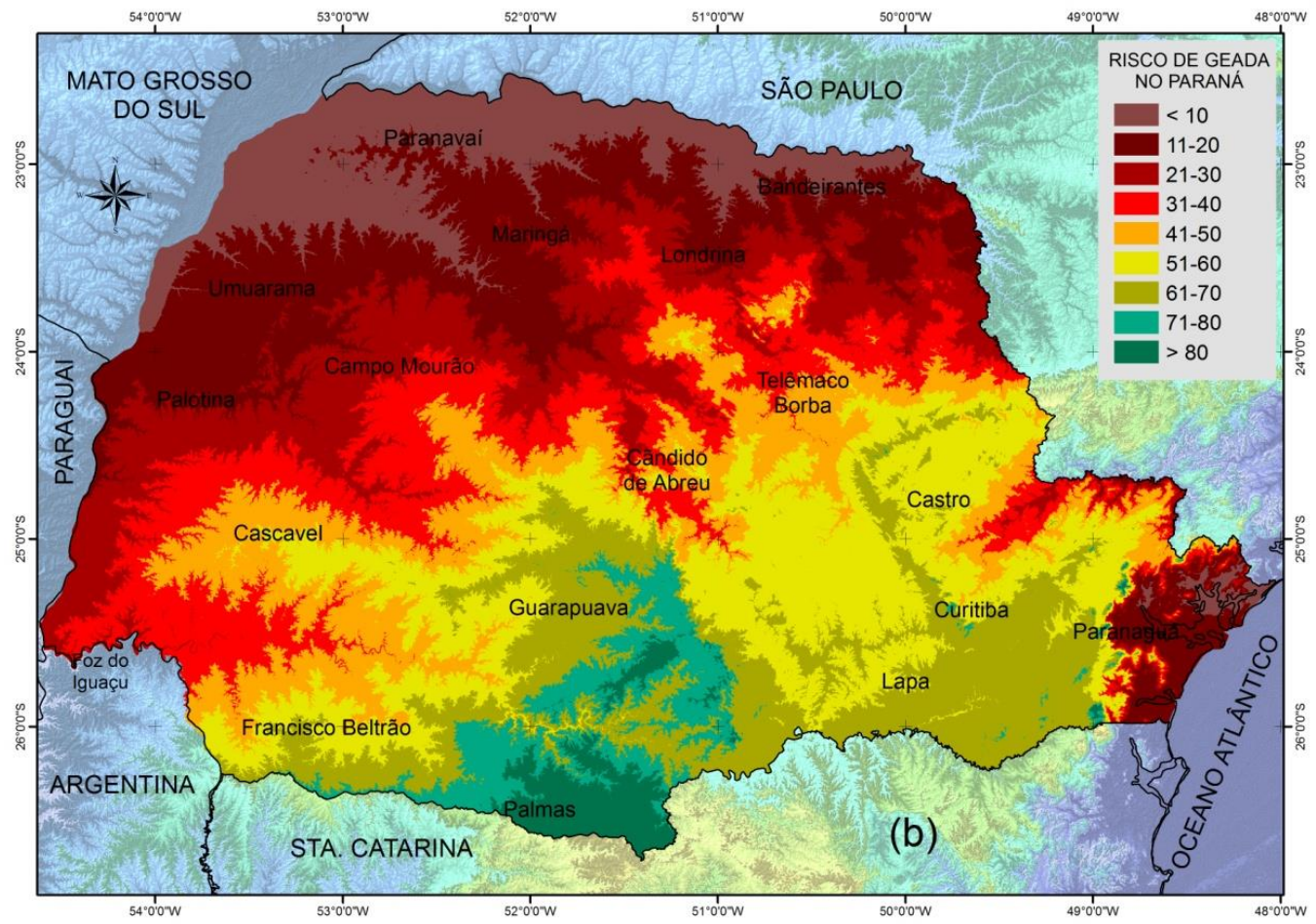

Figura 3b - Risco de ocorrência de geada no estado do Paraná no mês de junho (b).

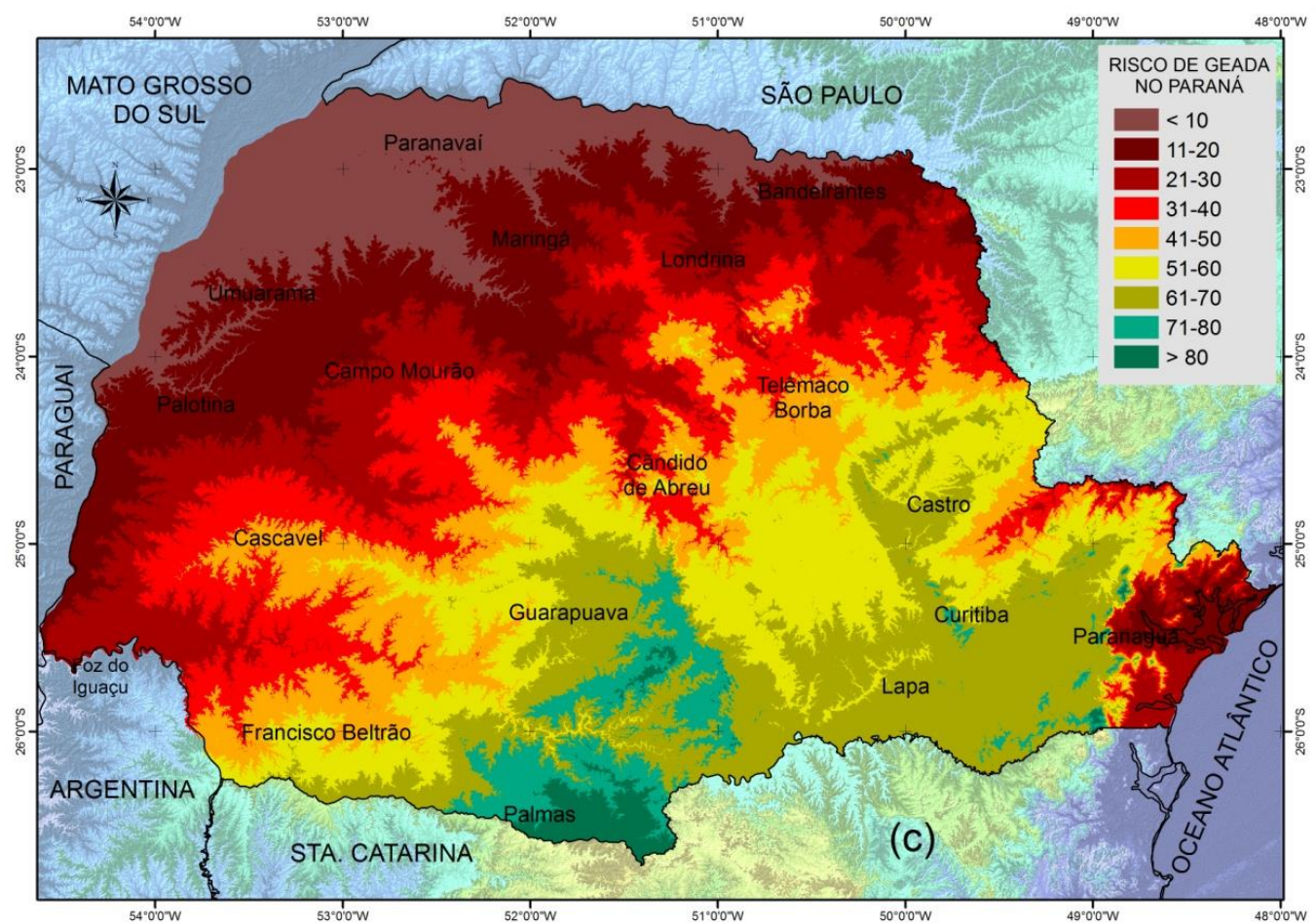

Figura 3c - Risco de ocorrência de geada no estado do Paraná no mês de julho (c). 


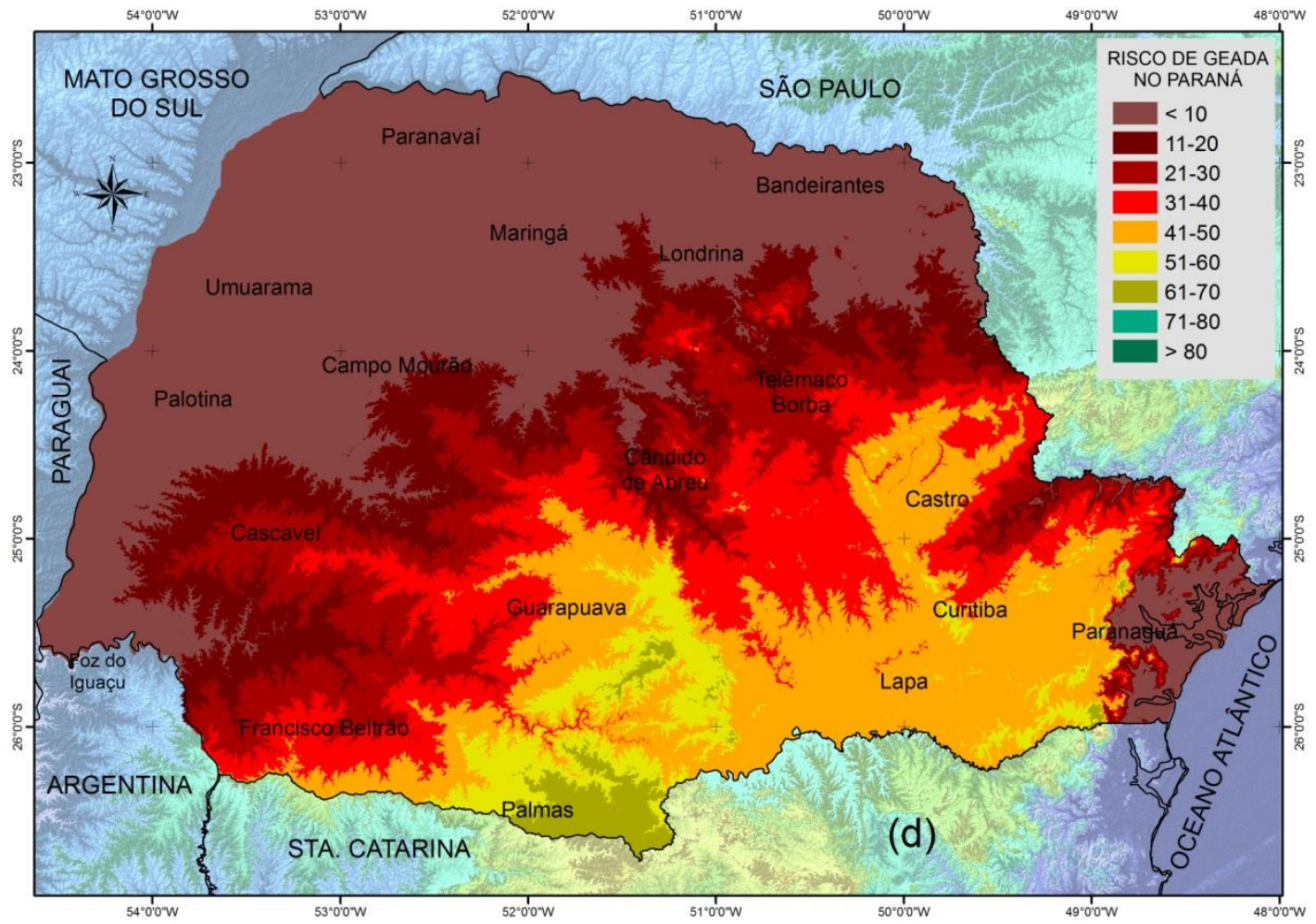

Figura 3d - Risco de ocorrência de geada no estado do Paraná no mês de agosto (d).

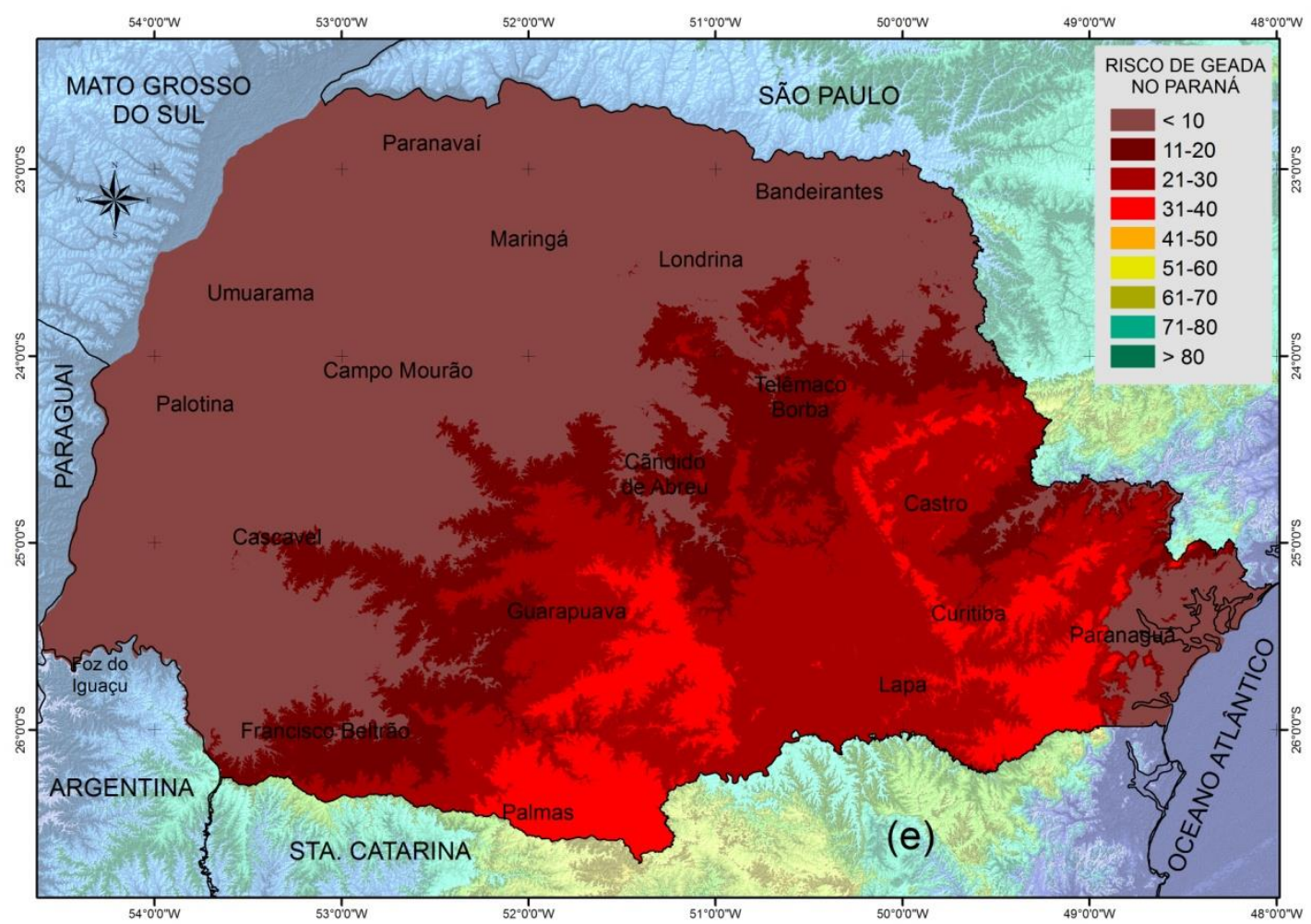

Figura 3e - Risco de ocorrência de geada no estado do Paraná no mês de setembro (e). 


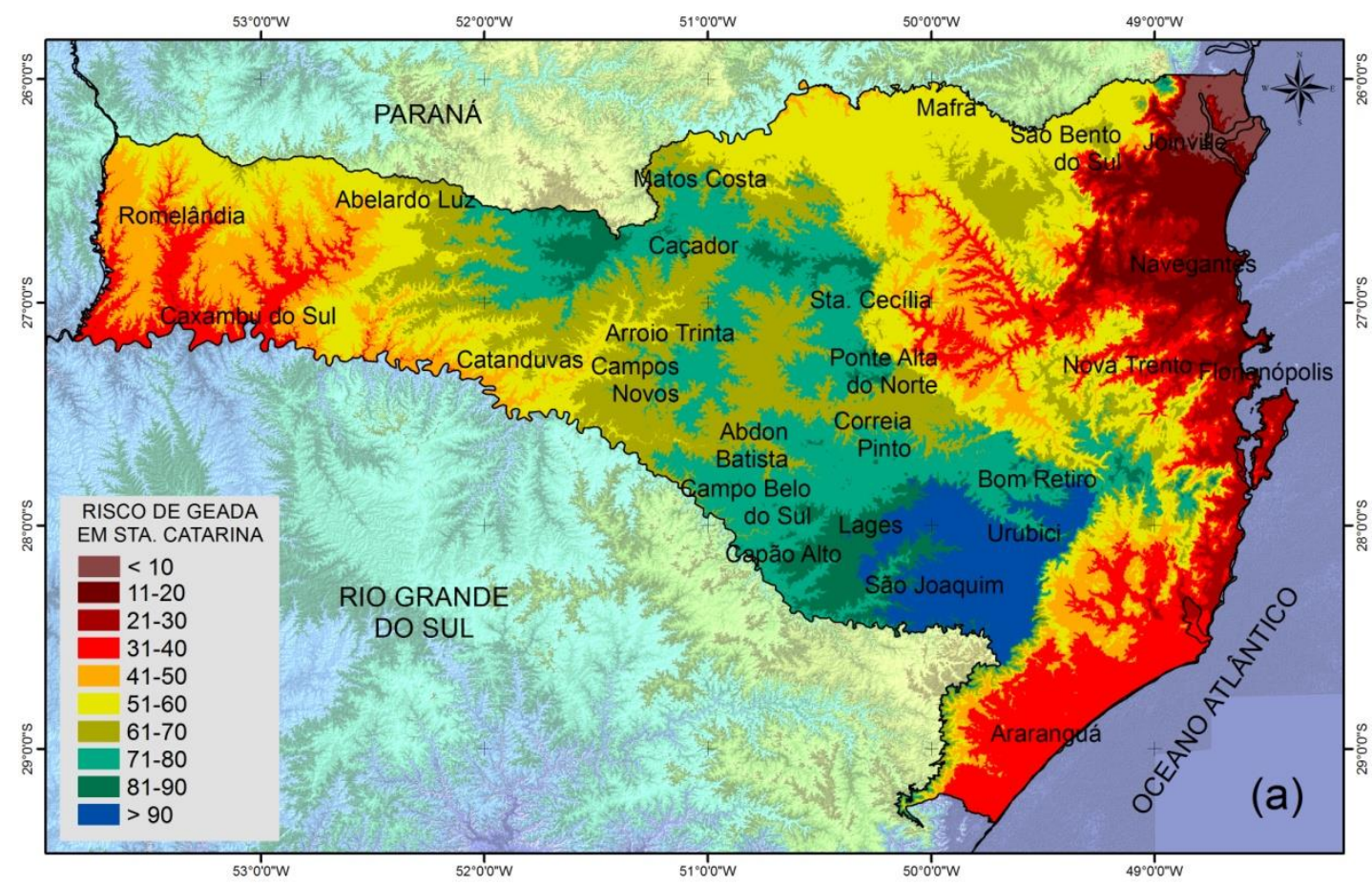

Figura 4a - Risco de ocorrência de geada no estado de Santa Catarina no mês de maio (a).

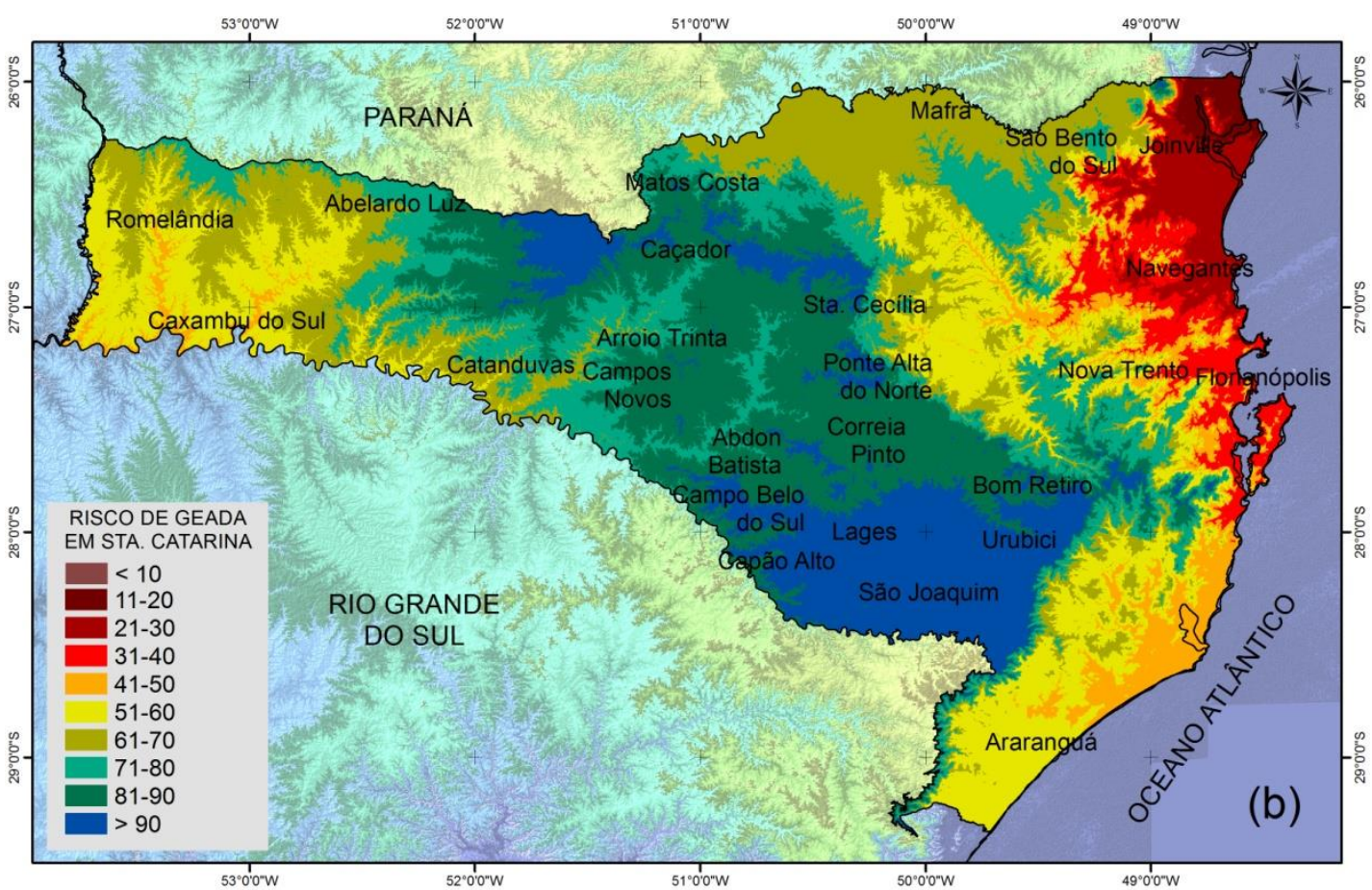

Figura 4b - Risco de ocorrência de geada no estado de Santa Catarina no mês de junho (b). 


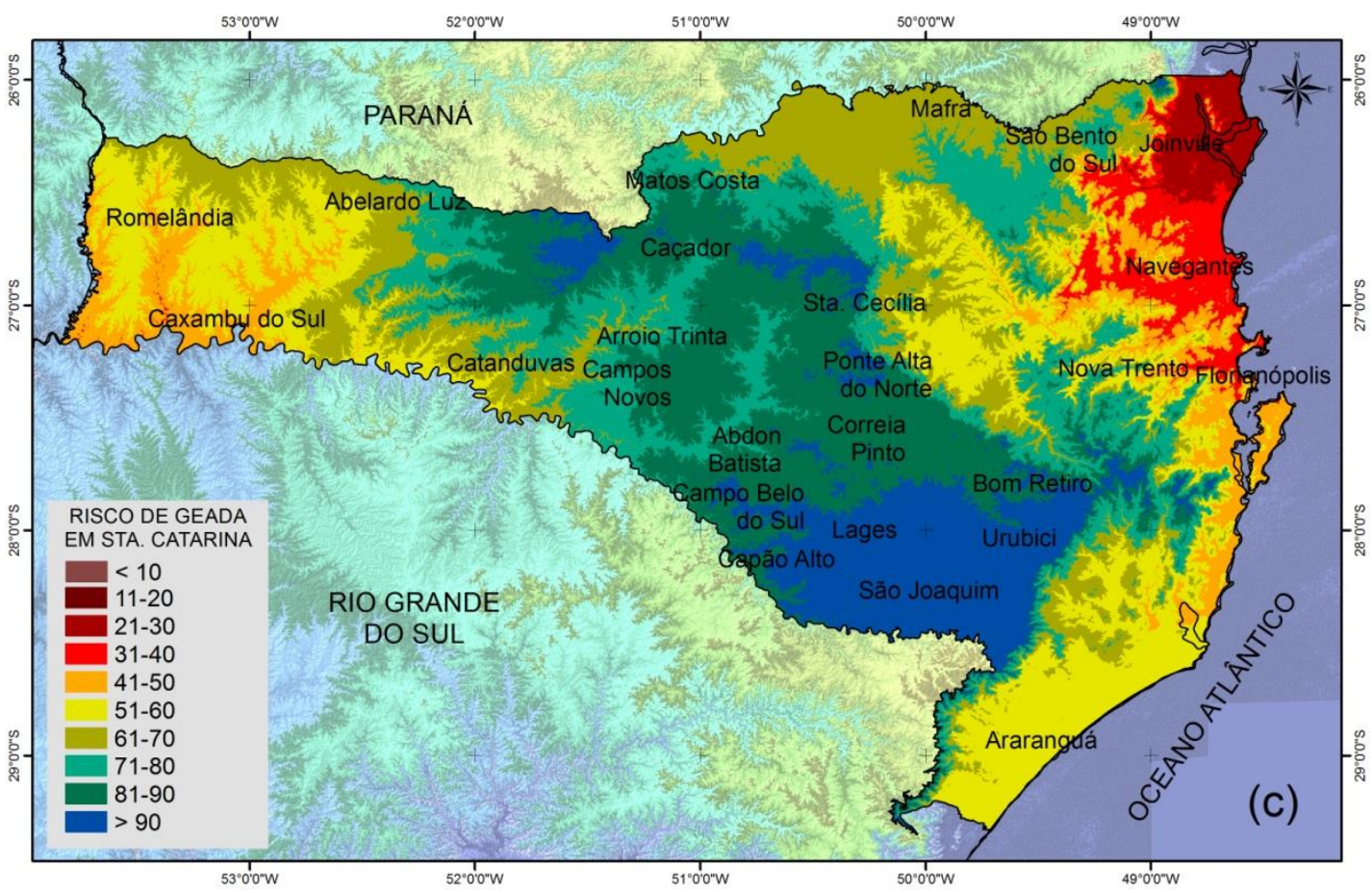

Figura 4c - Risco de ocorrência de geada no estado de Santa Catarina no mês de julho (c).

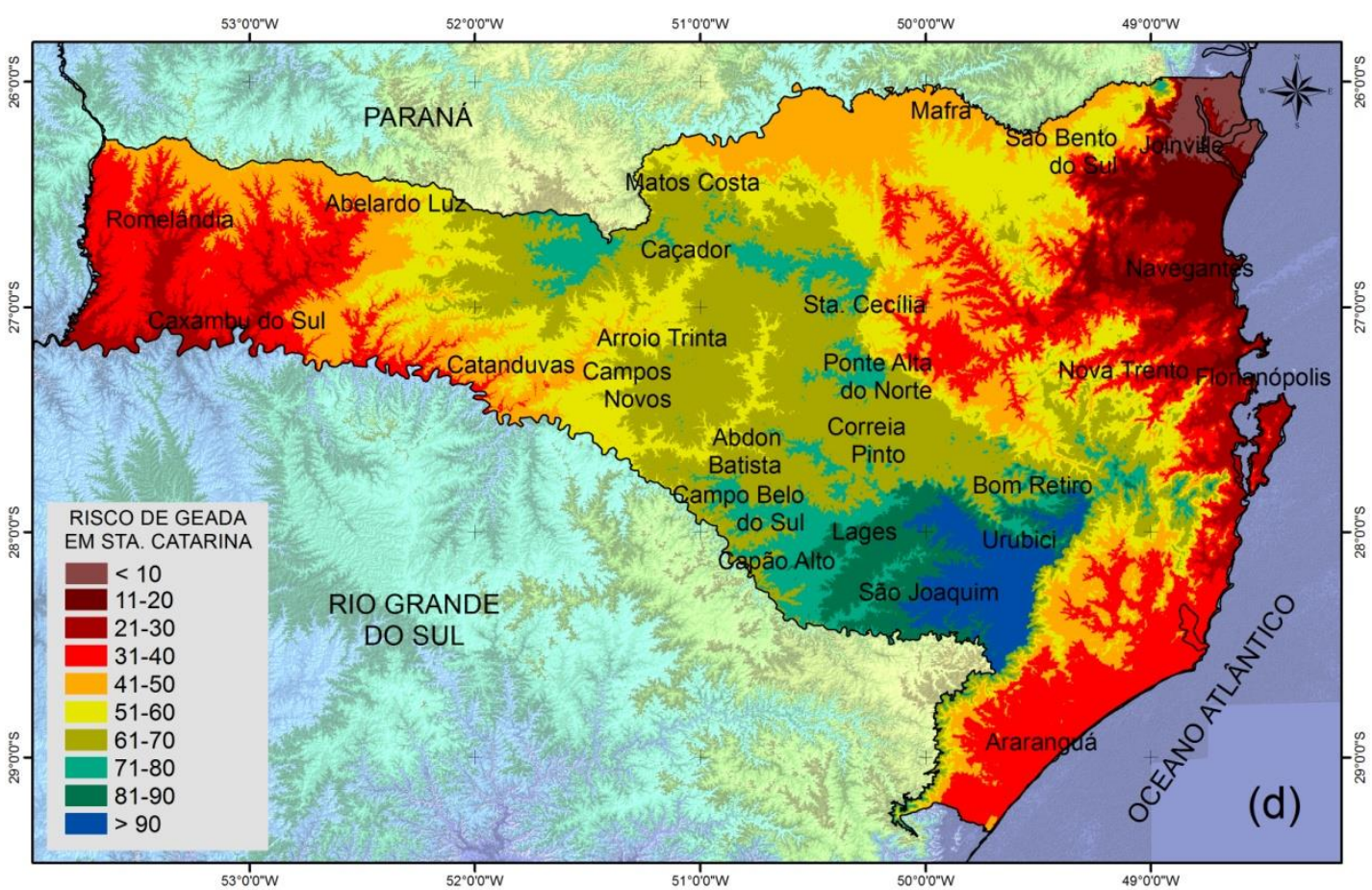

Figura 4d - Risco de ocorrência de geada no estado de Santa Catarina no mês de agosto (d). 


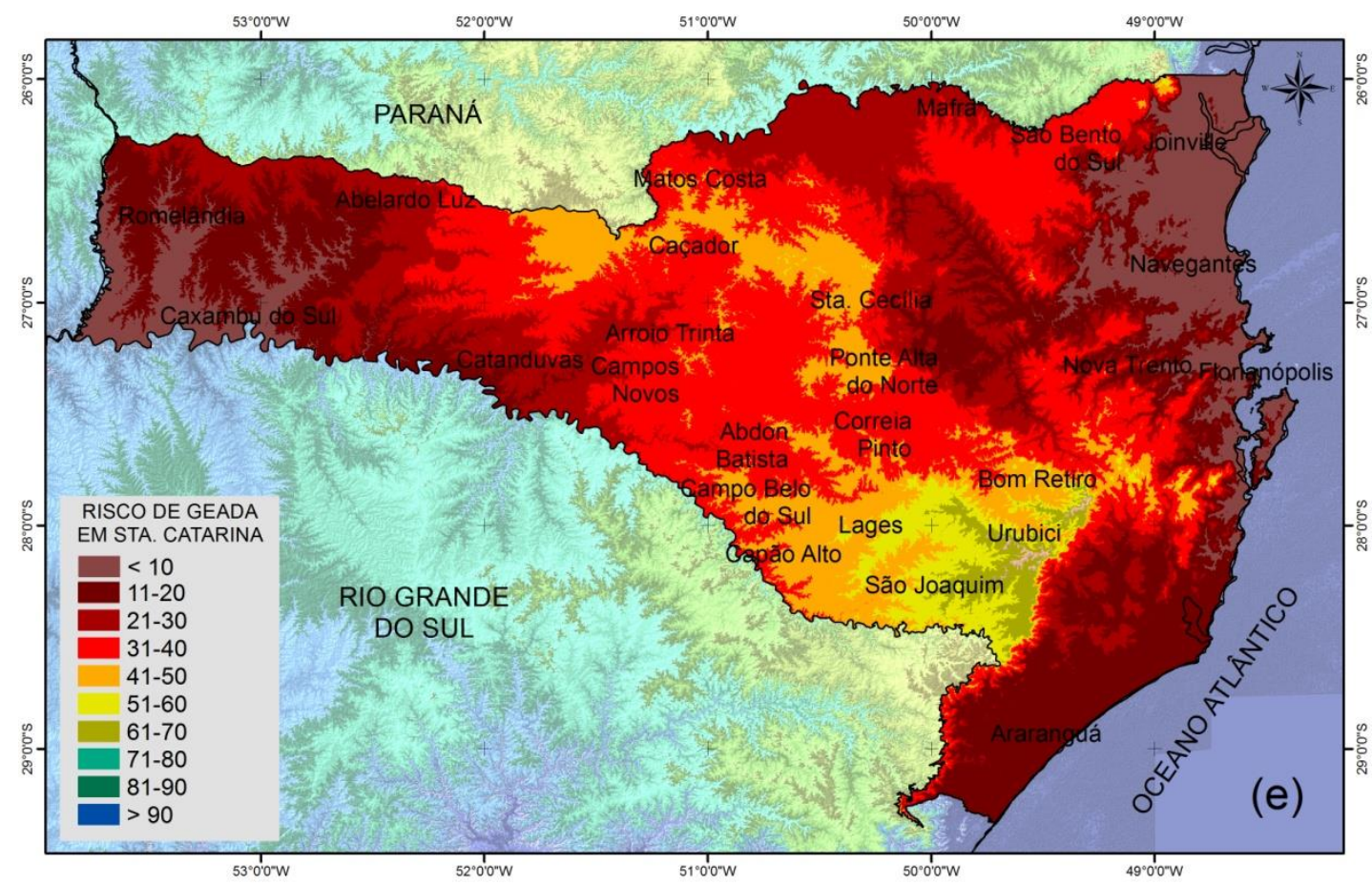

Figura 4e - Risco de ocorrência de geada no estado de Santa Catarina no mês de setembro (e).

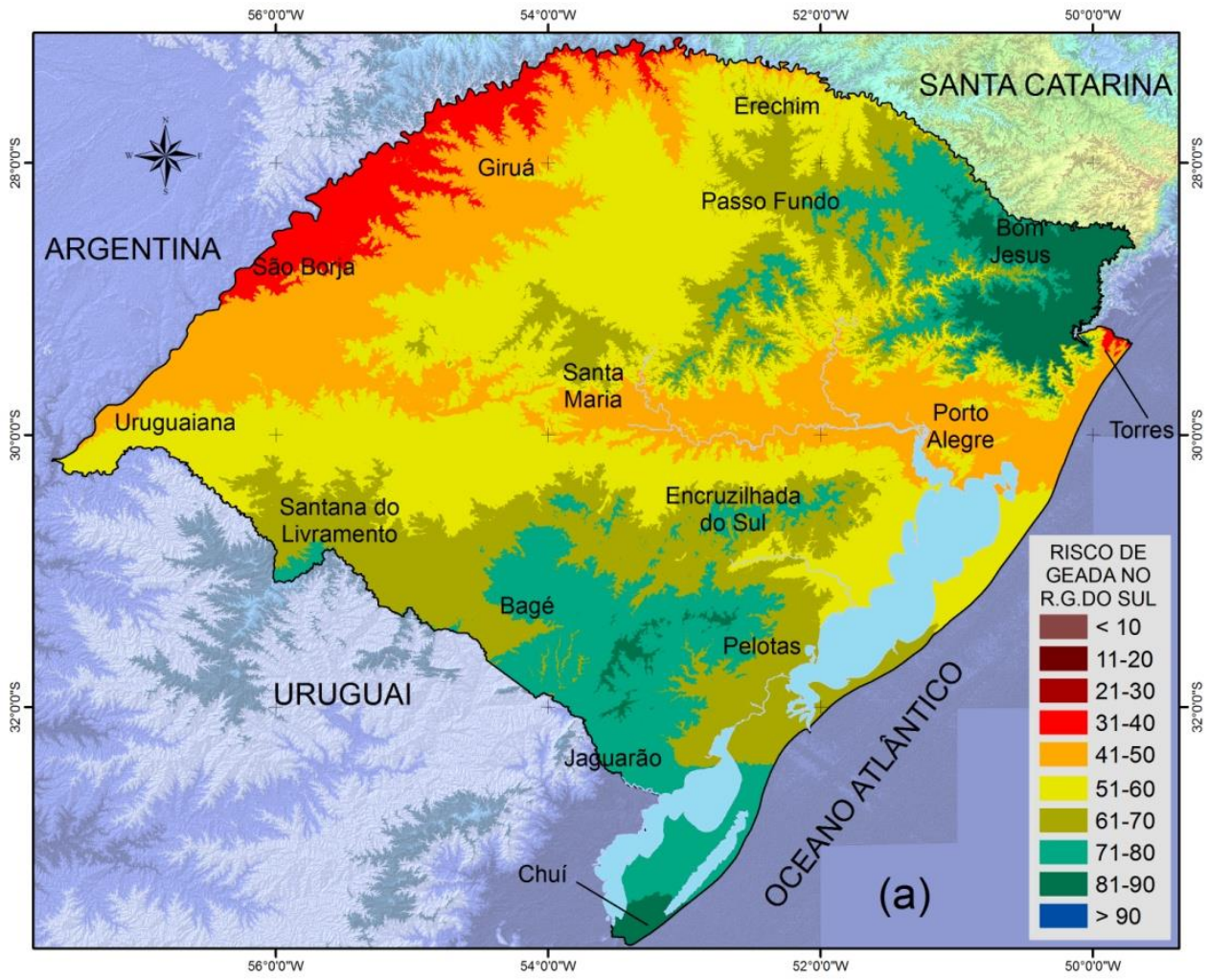

Figura 5a - Risco de ocorrência de geada no Rio Grande do Sul no mês de maio (a). 


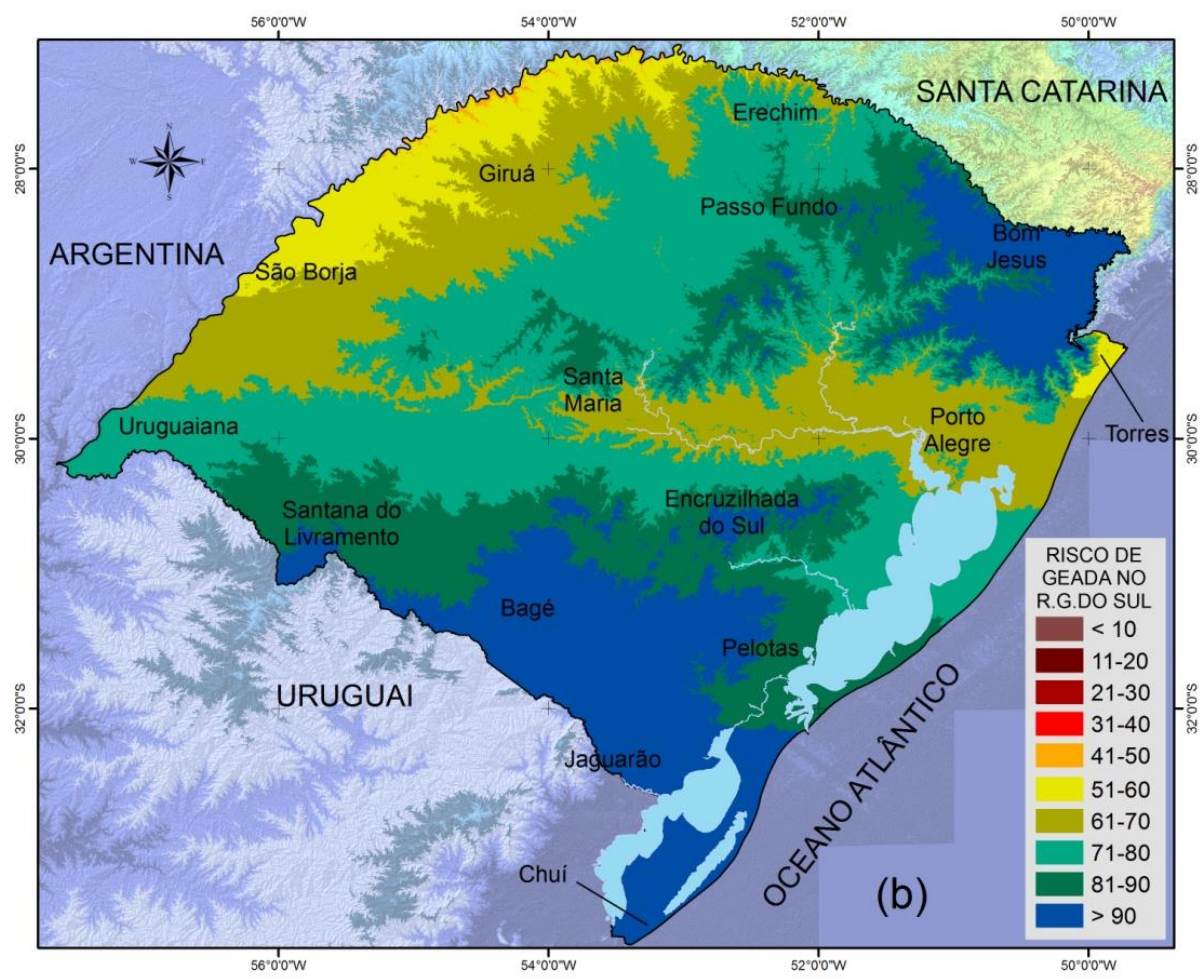

Figura 5b - Risco de ocorrência de geada no Rio Grande do Sul no mês de junho (b).

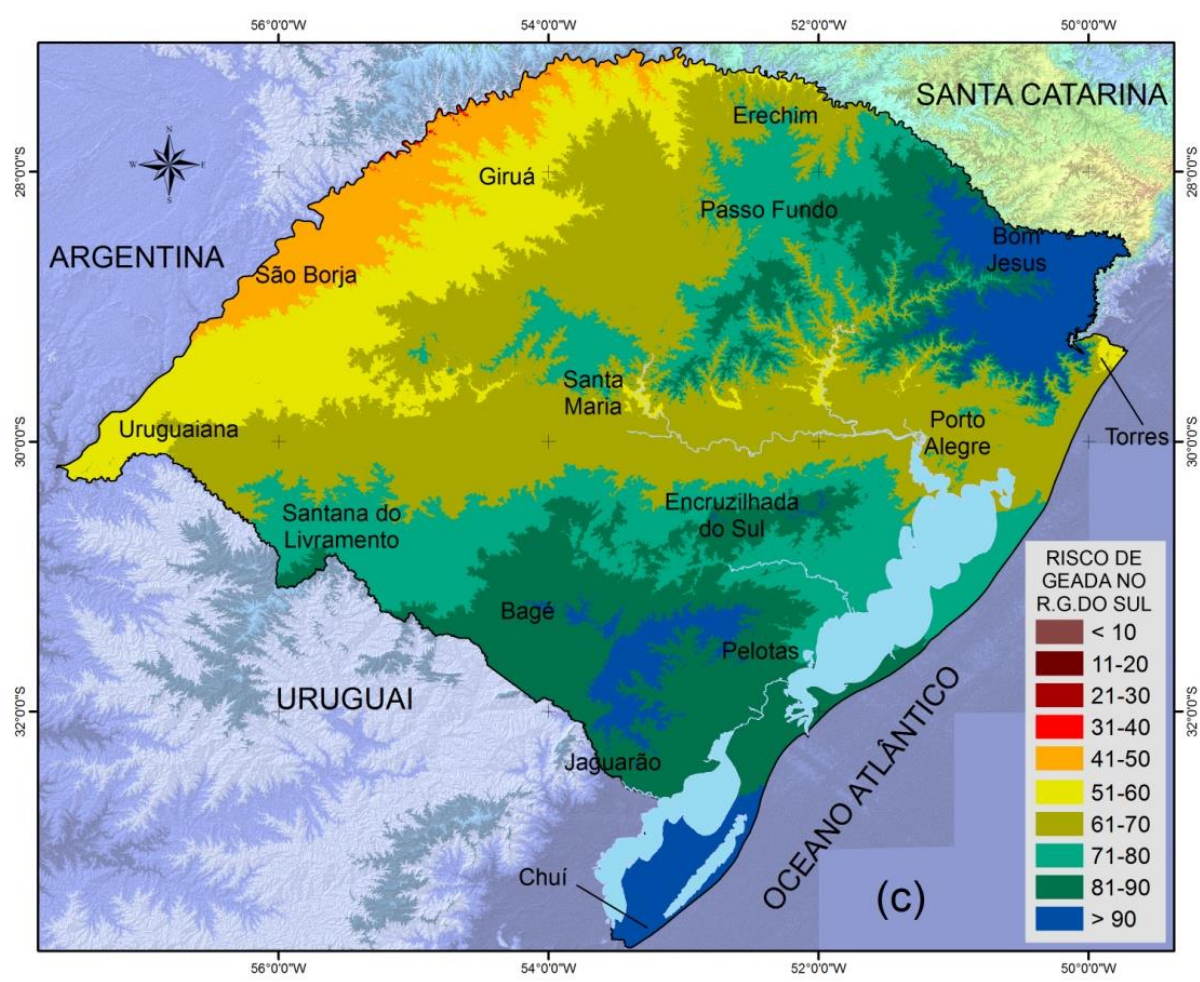

Figura 5c - Risco de ocorrência de geada no Rio Grande do Sul no mês de julho (c). 


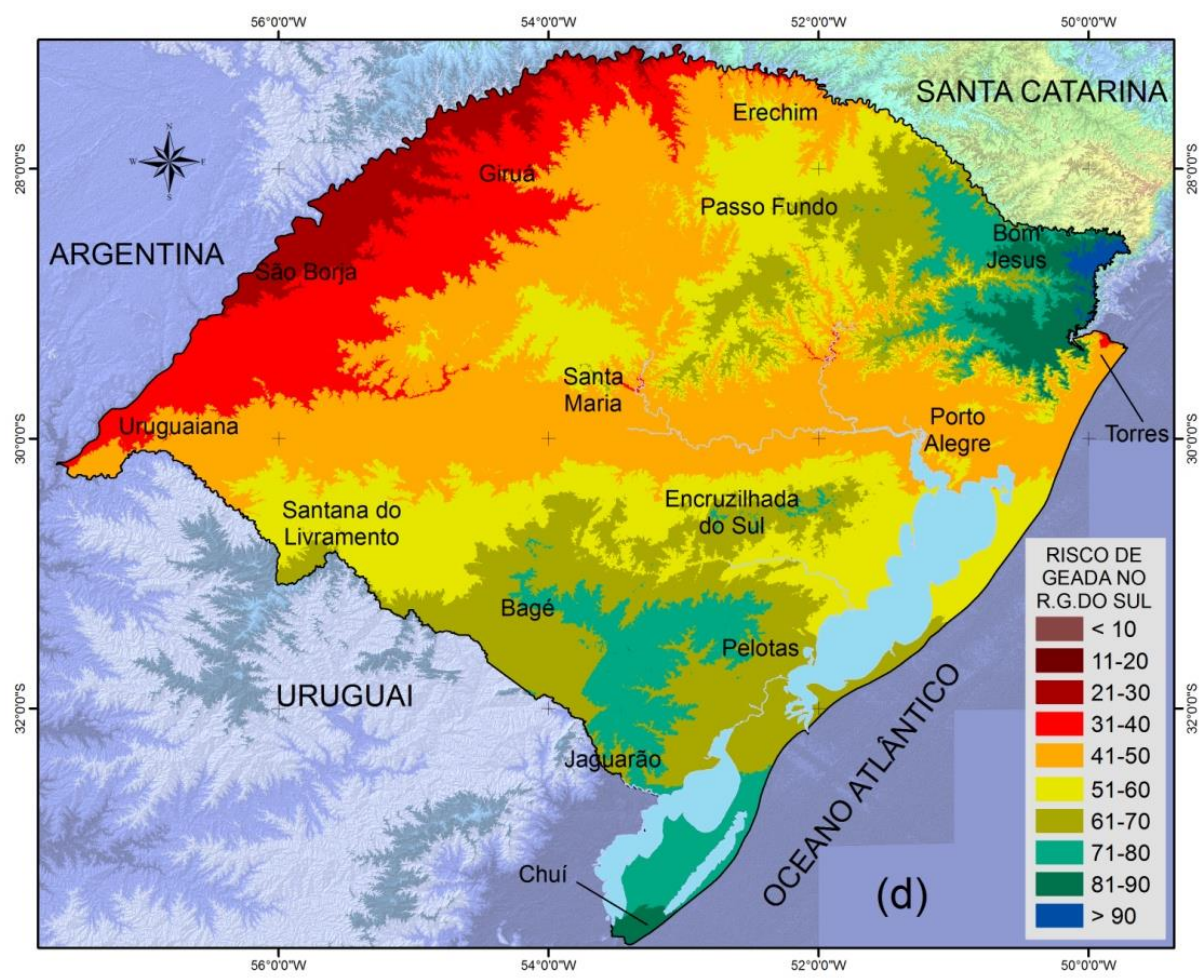

Figura 5d - Risco de ocorrência de geada no Rio Grande do Sul no mês de agosto (d).

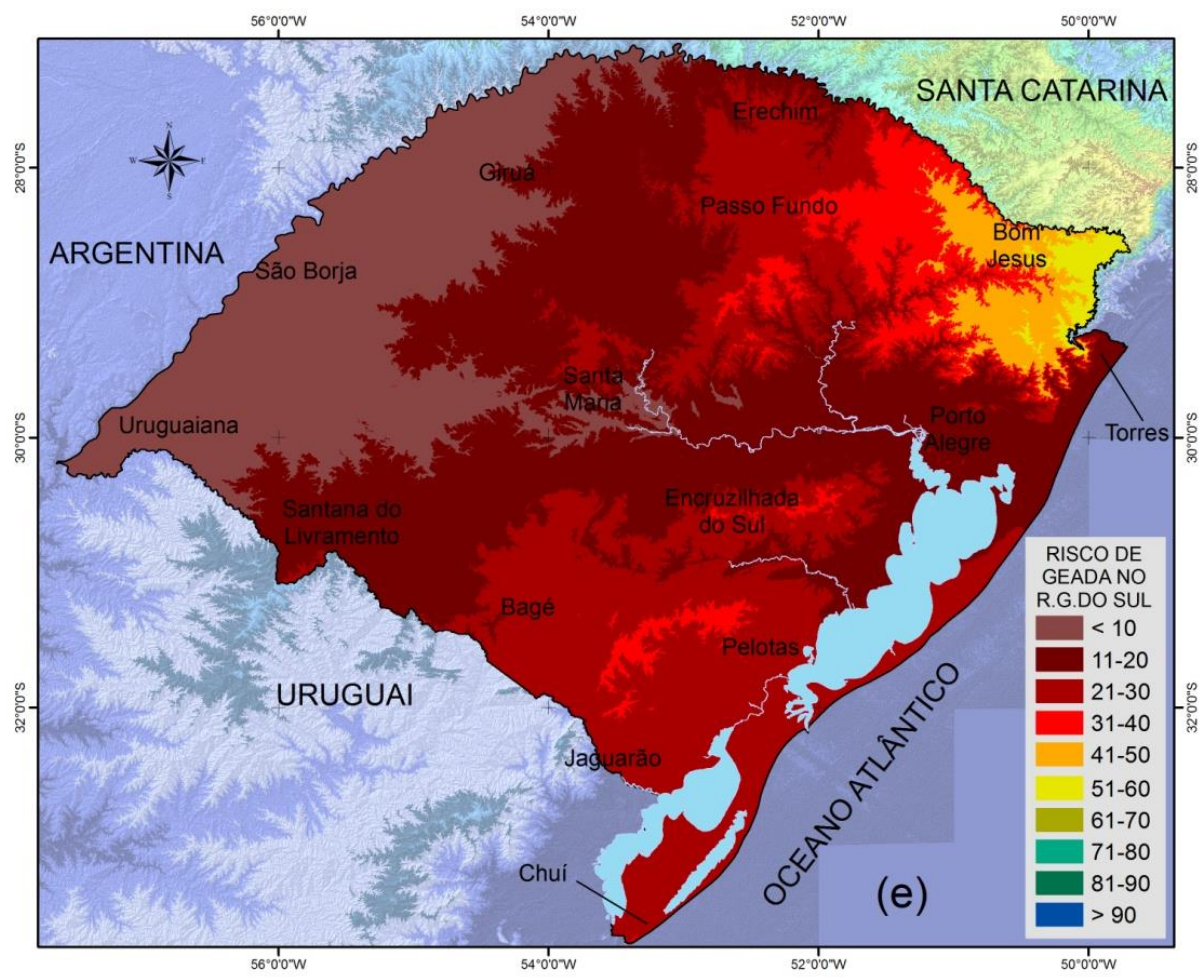

Figura 5e - Risco de ocorrência de geada no Rio Grande do Sul no mês de setembro (e). 
As Figuras 6 a 9 apresentam os gráficos de medianas (Box Plot) para altitude, risco de geada, latitude e longitude.

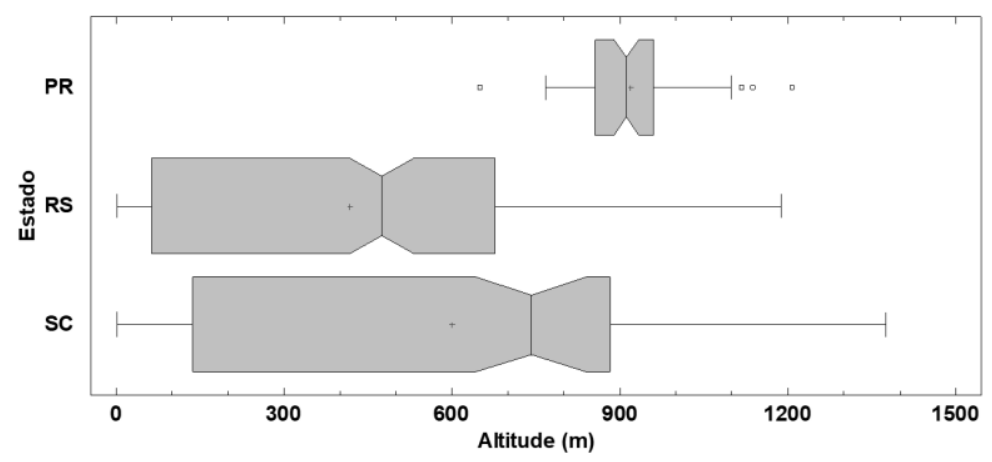

Figura 6 - Gráfico Box Plot para altitude nos locais com risco de geada maiores que $60 \%$ nos estados do Paraná (PR), Santa Catarina (SC) e Rio Grande do Sul (RS).

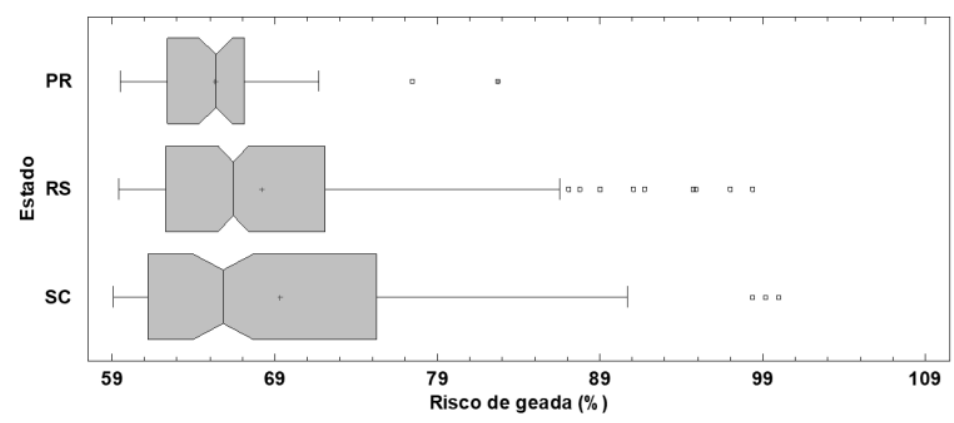

Figura 7 - Gráfico Box Plot para risco de geada nos locais com risco maiores que 60\% nos estados do Paraná (PR), Santa Catarina (SC) e Rio Grande do Sul (RS).

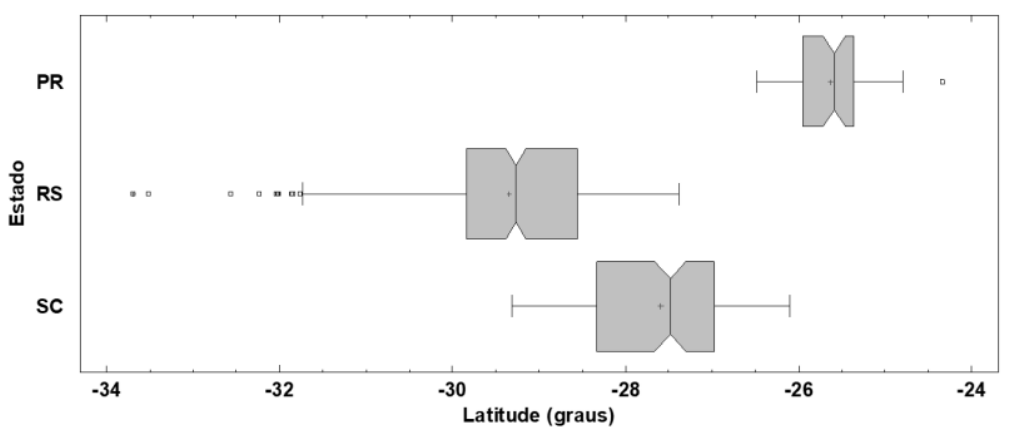

Figura 8 - Gráfico Box Plot para latitude nos locais com risco de geada maiores que $60 \%$ nos estados do Paraná (PR), Santa Catarina (SC) e Rio Grande do Sul (RS). 


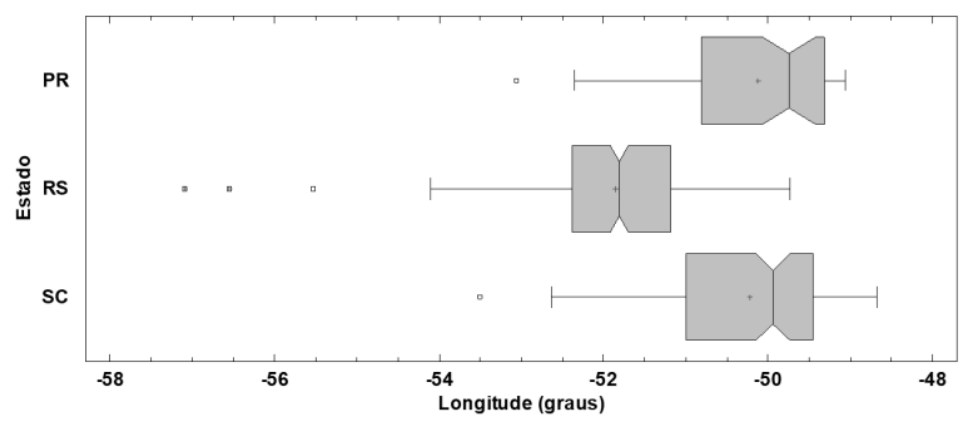

Figura 9 - Gráfico Box Plot para longitude nos locais com risco de geada maiores que $60 \%$ nos estados do Paraná (PR), Santa Catarina (SC) e Rio Grande do Sul (RS).

\section{DISCUSSÃO}

\section{RISCO DE GEADA, ALTITUDE, LATITUDE E LONGITUDE}

A correlação existente entre o alto risco de ocorrência de geada (maior que $60 \%$ ) e altitude é muito forte para o estado de São Paulo; moderada para Santa Catarina e fraca para os estados do Paraná e do Rio Grande do Sul (Tabela 2) (SANTOS, 2007). Quando são considerados todos os estados, a correlação é fraca.

O estado de São Paulo é o que apresenta a correlação mais forte. Em Campos do Jordão, um dos municípios com maior altitude e menor latitude do estado de São Paulo, na Serra da Mantiqueira, o risco de ocorrência de geada é maior (risco de $88 \%$, correspondendo a 9 anos com geada a cada 10 anos), em função da altitude em que o município se encontra; enquanto que para o litoral, o norte e noroeste de São Paulo e do Paraná, com menor altitude, o risco é menor. Diferentemente, Bagé, situado no extremo sul do Brasil, fronteira com o Uruguai, um dos municípios de menor altitude $(200 \mathrm{~m})$ e maior latitude do estado do Rio Grande do Sul, o risco de ocorrência de geada é maior (risco de $66 \%$, correspondendo a 7 anos com geada a cada 10 anos) em função da latitude em que o município se encontra. Do mesmo modo, o litoral do estado também apresenta alto risco de ocorrência de geada, apesar da altitude ser próxima ao nível do mar.

O maior risco de geada em função da maior altitude ocorre porque a temperatura do ar tem correlação inversa com a altitude, diminuindo pouco menos de $1^{\circ} \mathrm{C}$ a cada 100 metros de altitude, o que corresponde ao gradiente adiabático do ar seco. Na prática, para o estado do Paraná, MAACK (1981) encontrou alteração de $0,5{ }^{\circ} \mathrm{C}$ e OMETTO (1981), de 0,6 ${ }^{\circ} \mathrm{C}$, na média, para cada 100 metros de altitude, considerando o ar úmido. FRITZSONS et al. (2008) verificaram diminuição de $0,79{ }^{\circ} \mathrm{C}$ a cada 100 metros, observando também que a temperatura teve maior influência da altitude, sendo menos influenciada pela latitude e longitude. Verificaram ainda que a temperatura média anual apresenta variação de 0,54 a $1,17{ }^{\circ} \mathrm{C}$ para cada grau de latitude e de 0,22 a $0,72{ }^{\circ} \mathrm{C}$ para cada grau de longitude. 
Nos três estados do sul do país, a altitude onde o risco de geada é maior que $60 \%$, é significativamente diferente, pois observa-se a não sobreposição dos flancos das caixas (notched box plots) (Tabela 2 e Figura 6). Em ordem decrescente, os estados que tem a menor altitude média relacionada ao alto risco de ocorrência de geada são: Rio Grande do Sul (417 m); Santa Catarina (599 m) e Paraná (1029 m) (Tabela 3). No estado do Rio Grande do Sul, existe alto risco de ocorrência de geada em regiões com altitude inferior à altitude média do estado, inclusive em zonas situadas ao nível do mar, devido à compensação da altitude com a latitude.

Pelo teste de Kruskal Wallis, não houve diferença significativa entre os três estados em relação ao alto risco de ocorrência de geada (maior que 60\%) (Figura 7). No estado do Paraná, o risco de ocorrência de geada no mês de julho não passa de $83 \%$, enquanto que nos estados de Santa Catarina e do Rio Grande do Sul, muitos municípios possuem risco de geada em praticamente todos os anos (100\% de risco de ocorrência de geada). Entretanto, pelo teste de Kolmogorov-Smirnov (Tabela 3), na comparação entre estados dois a dois, Rio Grande do Sul e Santa Catarina não diferem estatisticamente entre si quanto ao risco de geada, mas diferem do Paraná, pois as geadas são mais frequentes em julho em Santa Catarina e no Rio Grande do Sul.

Não houve correlação entre o alto risco de ocorrência de geada (maior que $60 \%$ ) e a latitude (Figura 8), quando se analisou todos os estados, exceto São Paulo, cuja correlação foi moderada e negativa, ou seja, quanto maior a latitude menor o risco de geada (risco de geada maior que 60\%). No caso de São Paulo, a correlação negativa ocorre devido à posição da Serra da Mantiqueira, situada na porção nordeste do estado, onde as geadas ocorrem com maior frequência.

Para os estados de Santa Catarina e do Rio Grande do Sul, as correlações entre o risco de ocorrência de geada (maior que 60\%) e a longitude foram pouco significativas. Para os estados do Paraná e de Santa Catarina, os maiores riscos de geada (maiores que 60\%) ocorrem nas zonas de longitudes intermediárias, onde o relevo apresenta altitudes maiores, mas não diferem significativamente entre si, o que pode ser visualizado no gráfico Box Plot (Figura 9 e Tabela 3).

\section{RISCO DE GEADA POR ESTADO}

\section{SÃO PAULO}

No estado de São Paulo, de modo geral, o risco de geada é menor, exceto nas regiões de maior altitude. Os maiores riscos encontram-se nos municípios de Campos do Jordão (1603 m) e região, onde a temperatura mínima absoluta estimada chega a $-7,08{ }^{\circ} \mathrm{C}$ (WREGE et al., 2011), Santo Antônio do Pinhal (1113 $\mathrm{m})$, Bom Sucesso de Itararé (968 m), Apiaí (909 m), Pedra Bela (1093 m), Itapecerica da Serra (906 m), Cunha (936 m), entre outros municípios de maior altitude do estado, com risco variando entre 50 a $60 \%$, o que representa, na média, ocorrência de geada em 5 a 6 anos em cada 10 anos. Para o município de Campos do Jordão e região, os riscos chegam a pouco mais de $88 \%$, o que representa, na média, 9 anos com geada a cada 10 anos, confirmando as informações de CAMARGO et al. (1993). A região do litoral, o norte e oeste do estado possuem risco muito baixo de ocorrência de geada, praticamente não apresentam risco. 
Assim, no estado de São Paulo, a ocorrência de geada (maior que 60\%) está fortemente relacionada à altitude $(R=0,92)$ (Tabela 2), devido à forte variação deste parâmetro em uma região de transição climática (Trópico de Capricórnio). A correlação do risco de geada com a latitude é moderada $(R=-$ $0,45)$ e com a longitude, fraca $(R=0,31)$. As geadas mais fortes estão concentradas no norte do estado, na Serra da Mantiqueira.

O risco de geada em setembro é baixo ("zero" na maior parte do estado), menor que o dos estados do sul do país. Por essa razão, não foi apresentado o mapa de risco de geada em setembro para o estado de São Paulo.

\section{PARANÁ}

No Paraná, os riscos são maiores, se comparados ao estado de São Paulo, pois o estado está situado em uma faixa de latitudes mais meridionais e, no sul do estado, há predominância de altitudes maiores, principalmente nos municípios de Palmas (1072 m de altitude), General Carneiro (1091 m) e Guarapuava (1051 m), onde as temperaturas mínimas absolutas variam entre $2,19{ }^{\circ} \mathrm{C}$ e $-4,28{ }^{\circ} \mathrm{C}$ (WREGE et al., 2015; 2011). Nesta região, o risco de geada pode ultrapassar $60 \%$, representando 6 a 8 anos com geada, na média, a cada 10 anos, confirmado pelos dados de ZAICOVSKI et al. (2008). Essa região pode ser considerada como uma das que se apresentam com as menores temperaturas do Brasil e os maiores riscos de ocorrência de geada, com clima do tipo temperado, segundo a classificação de Köeppen. Ao contrário, no norte do estado, no vale do Paranapanema e no vale do Ivaí e, ainda, na zona costeira, os riscos são menores (menos de 1 a 2 anos com geada a cada 10 anos, na média) devido à altitude menor, apresentando respectivamente clima subtropical ( $\mathrm{Cfa}$ ) (norte e região dos vales) e tropical (Af) (litoral) (WREGE et al., 2011). A fraca correlação do risco de geada (maior que 60\%) com a altitude $(R=0,43)$ é devida a maior altitude dos municípios em que esse risco ocorre no estado, isto é, não há muita variação da altitude (está sempre relacionada à maior altitude, sem exceção), na zona classificada por Köeppen como de clima temperado (Cfb). Não há correlação entre o risco de ocorrência de geada (maior que $60 \%$ ) e a latitude e a longitude.

\section{SANTA CATARINA}

Em Santa Catarina, a parte central do estado, representada pelo Planalto Ocidental, apresenta-se com clima temperado (Cfb, na classificação de Köeppen), sendo dominada por altitudes maiores, favorecendo a ocorrência de temperaturas menores e maior risco de ocorrência de geada, principalmente no sul, nas regiões serranas, onde a altitude é maior que 800 metros, como nos municípios de Lages (985 m), São Joaquim (1412 m), Bom Jardim da Serra (1018 m), Urupema (1234 m), Urubici (1262 m), Capão Alto (965 m), entre outros, com temperaturas mínimas absolutas variando entre $-4,71^{\circ} \mathrm{C}$ e $-8,80$ ${ }^{\circ} \mathrm{C}$ (WREGE et al., 2015; 2011) (Tabela 4). Essa região, junto ao sul do Paraná, apresenta-se com as menores temperaturas do país e os maiores riscos de ocorrência de geada. Os riscos variam entre 60 e $90 \%$, podendo ser maiores que $90 \%$ nas zonas de maior altitude destes municípios, ocorrendo geada, portanto, em pelo menos 6 e 9 anos, a cada 10 anos, ou seja, em muitos 
municípios existe a possibilidade de ocorrência de geada em quase todos os anos.

A parte leste do estado (Planície Costeira, Planície Fluvial, Serra Geral, Serras do Leste Catarinense e Serra do Mar) apresenta altitudes que variam de 0 a 200 m e a parte oeste, nos Planaltos do Rio Iguaçu e Rio Uruguai, altitudes de 200 a $800 \mathrm{~m}$. Por causa da altitude menor, apresenta-se com temperaturas maiores e clima do tipo subtropical (Cfa, na classificação de Köeppen), com baixo risco de ocorrência de geada. Na região costeira, o risco de geada é menor devido à menor altitude e o efeito de maritimidade, onde existe a ação termorreguladora do oceano, observando-se diferença entre o norte e o sul do estado onde, neste último caso, o risco de geada é um pouco maior devido à maior latitude (AGUIAR; MENDONZA, 2004).

A correlação do risco de geada (maior que $60 \%$ ) com a altitude $(R=0,68)$ e com a latitude $(R=0,64)$ é moderada (Tabela 2 ) e é pouco significativa para a longitude.

\section{RIO GRANDE DO SUL}

No estado do Rio Grande do Sul, existem duas regiões serranas representadas pela Serra do Nordeste, situada ao norte e com altitudes maiores, como São José dos Ausentes (1263 m), São Francisco de Paula (890 m), Bom Jesus $(1066 \mathrm{~m})$, Cambará do Sul $(1025 \mathrm{~m})$, entre outras, com temperaturas mínimas absolutas variando, na média, entre $-6,39{ }^{\circ} \mathrm{C}$ e $-8,00{ }^{\circ} \mathrm{C}$, e a Serra do Sudeste, situada no sul do estado e com altitudes bem inferiores à primeira, que não ultrapassam os 400 metros - Canguçu (326 m), Piratini (251 m), Pedras Altas $(269 \mathrm{~m})$, Herval $(252 \mathrm{~m})$, entre outros, com temperaturas mínimas absolutas variando, em média, entre $-1,99{ }^{\circ} \mathrm{C}$ a $-2,72{ }^{\circ} \mathrm{C}$ (WREGE et al., 2015; 2011). O clima nestas duas regiões é do tipo temperado, segundo a classificação de Köeppen, com alto risco de ocorrência de geada, havendo 8 anos com geada, na média, a cada 10 anos. No litoral norte e na Depressão Central, o risco de ocorrência de geada ainda é elevado, com cerca de 6 anos de geada, na média, a cada 10 anos. A zona de menor risco de ocorrência de geada no estado fica no Alto Vale do Uruguai, caracterizada por ter menos de 5 anos com geada a cada 10 anos, sendo uma das zonas de menor altitude do estado, depois da zona costeira. Nessa região, o clima é do tipo subtropical (Cfa).

Em virtude do estado do Rio Grande do Sul estar situado na porção mais meridional do sul do país, em latitudes maiores, e estar sujeito à entrada das frentes frias vindas do sul, a correlação entre o risco de geada e altitude é fraca $(R=0,49)$, não há correlação com a latitude $e$, com a longitude, é pouco significativa.

No Rio Grande do Sul, a dinâmica das massas de ar tem ação decisiva na distribuição térmica e pluviométrica do estado, que sofre a ação de basicamente três tipos diferentes de massas de ar, quente tropicais e ou frias polares, sendo: 1) massa tropical Atlântica, caracterizada por ser quente e úmida, formada no Oceano Atlântico em área tropical, dispersora de ventos quentes; 2) massa de ar polar Atlântica, caracterizada por ser muito fria, formada sobre o oceano no sul da Argentina e, ainda 3) massa tropical continental, caracterizada como quente e seca, formada sobre a região do Chaco (PEREIRA BRITO el at, 2008). 
Assim, de forma mais evidente que nos outros estados, o alto risco de ocorrência de geada no estado do Rio Grande do Sul é devido à entrada das frentes frias vindas do sul, havendo uma correlação mais fraca com a altitude, a latitude e a longitude.

\section{CONCLUSÕES}

O Centro-Sul do Brasil, principalmente os estados do Paraná e de São Paulo, situam-se em latitudes médias, na zona de transição climática do Trópico de Capricórnio, e apresenta relevo de altitude, o que confere variação de temperatura e do risco de ocorrência de geada, situado entre 0 e $88 \%$.

As menores temperaturas mínimas absolutas e, consequentemente, os maiores riscos de ocorrência de geada (maiores que 60\%), encontram-se na faixa que varia entre o sul do Paraná e o Rio Grande do Sul, nas zonas com altitudes maiores que 417 m no Rio Grande do Sul, 599 m em Santa Catarina e 1029 m no Paraná.

As regiões dos vales de rios no Centro-Sul do Brasil possuem menor risco de ocorrência de geada, em função da menor altitude, exceto no estado do Rio Grande do Sul.

Para o estado do Rio Grande do Sul, o alto risco de ocorrência de geada (maior que 60\%), apresenta correlação fraca com a altitude, pois o fato do estado estar situado na zona de maior latitude do Brasil é de importância maior.

Os estados de Santa Catarina e do Rio Grande do Sul não se diferenciam estatisticamente em relação ao nível de risco de ocorrência de geada (maior que $60 \%$ ), havendo municípios com até $100 \%$ de risco, isto é, onde ocorrem geadas todos os anos, enquanto que para o estado do Paraná, os maiores riscos de geada chegam a pouco mais de $80 \%$.

Com o histórico de mais de dez anos da rede de estações meteorológicas automáticas no sul do Brasil, cujos dados climáticos são registrados na escala temporal horária, pode-se melhorar os estudos de ocorrência de geada, pois o tempo em que a temperatura permanece baixa apresenta forte relação com os danos causados às plantas e isto não era possível avaliar com as estações meteorológicas convencionais.

\section{AGRADECIMENTOS}

Ao IAC, ao IAPAR, à Epagri e ao Departamento de Diagnóstico e Pesquisa Agropecuária - DDPA, da Secretaria da Agricultura, Pecuária e Irrigação - SEAPI do Rio Grande do Sul, pela cessão dos dados climáticos.

À Embrapa, pelo apoio financeiro (Projeto ARAUCAMATE) e logístico.

\section{REFERÊNCIAS BIBLIOGRÁFICAS}

Aguiar, D; Mendonça, M. Climatologia das geadas em Santa Catarina. In: SIMPÓSIO BRASILEIRO DE DESASTRES NATURAIS, 1, 2004. Florianópolis. Anais. Florianópolis: p.762-773 (CD-ROM). 
Alvares, C.A.; Sentelhas, P.C.; Stape, J.L. Modeling monthly meteorological and agronomic frost days, based on minimum air temperature, in Center-Southern Brazil. Theor. Appl. Climatol., 2017. DOI: 10.1007/s00704-017-2267-6.

Astolpho, F. Estimativa e mapeamento da probabilidade de ocorrência de temperaturas mínimas absolutas do ar adversas à agricultura paulista. Dissertação (mestrado em agricultura tropical e subtropical) - Instituto Agronômico. 99 p., 2003.

Berlato, M.A.; Althaus, D. Tendência observada da temperatura mínima e do número de dias de geada do Estado do Rio Grande do Sul. Pesquisa Agropecuária Gaúcha, Porto Alegre, v. 16, n. 1 e 2, p. 7-16, 2010.

Camargo, M.B.P.; Pedro Júnior, M.J.; Alfonsi, R.R.; Ortolani, A.A.; Brunini, O. Probabilidade de ocorrência de temperaturas mínimas absolutas mensais e anual no estado de São Paulo. Bragantia, Campinas, v.52, n.2, p. 161-168, 1993.

Caramori, P.H.; Leal, A.C.; Moraes, H. Temporary shading of young coffee plantations with pigeonpea (Cajanus cajan) for frost protection in Southern Brazil. Revista Brasileira de Agrometeorologia, Santa Maria, v.7, n.2, p.1-4, 1999.

Caramori, P.H.; Manetti Filho, J.; Moraes, H. et al. Geada - Técnicas para proteção dos cafezais. Londrina: IAPAR, 2000. 35 p. (Circular, 112).

Ferreira, M. A aventura dos eucaliptos. In: Schumacher, M.V.; Vieira, M. (ed.). Silvicultura do eucalipto no Brasil. Santa Maria, Editora UFSM, p. 13-48, 2015.

Fritzsons, E. Relação entre altitude e temperatura: uma contribuição ao zoneamento climático no estado do Paraná. Revista de Estudos Ambientais, v. 10 , p. $40-48,2008$.

Garcia, C.H.; Santos, P.E.T. Danos ocasionados pelas geadas no estado de São Paulo. Florestar Estatístico, v.2, p.23-24, 1995.

Grodzki, L. et al. Risco de ocorrência de geada no Estado do Paraná. Revista Brasileira de Agrometeorologia, Santa Maria, v. 4, n. 1, p. 93-99, 1996.

IBGE. Instituto Brasileiro de Geografia e Estatística. Malha municipal digital do Brasil, 2001, Rio de Janeiro, 2001. 1 CD-ROM.

Maack, R. Geografia Físicas do estado Paraná, 2a.Ed., Rio de Janeiro, J. Olympio, 1981.

Nimer, E., Climatologia do Brasil. Superintendência de Recursos Naturais e Meio Ambiente (SUPREN). Rio de Janeiro. IBGE. 422 p., 1979.

Ometto. J. C. Bioclimatologia vegetal. São Paulo: Ed. Agronômica Ceres. 1981. p. $129-132$.

Pereira Britto, F.; Barletta, R.; Mendonça, M. Regionalização sazonal e mensal da preciptação pluvial máxima no estado do Rio Grande do Sul. Revista Brasileira de Climatologia, [S.I.], v. 3, ago. 2008. ISSN 2237-8642. Disponível em: <http://revistas.ufpr.br/revistaabclima/article/view/25425/17044>. Acesso em: 09 ago. 2017. doi:http://dx.doi.org/10.5380/abclima.v3i0.25425.

Pinto, H.S.; Ortolani, A.A.; Alfonsi, R.R. Estimativa das temperaturas médias mensais do estado de São Paulo em função de altitude e latitude. São Paulo: Instituto de Geografia, FFCL, USP, 1972. 20p. (Caderno Ciências da Terra, 23). 
Pinto, H.S.; Zullo Jr., J.; Assad, E.D.; Brunini, O.; Alfonsi, R.R.; Coral, G. Zoneamento de riscos climáticos para a cafeicultura do estado de São Paulo. Revista Brasileira de Agrometeorologia, Passo Fundo, v.9, n.3, p. 495-500, 2001.

Sansigolo, C.A.; Nery, J.T. Distribuição de extremos de temperatura mínima no estado do Paraná. Revista Brasileira de Agrometeorologia, v.8, n.2, p. 247-253, 2000.

Santos, C. Estatística Descritiva - Manual de auto aprendizagem, Lisboa. Edições Silabo. 264p. 2007

Silva, J.G.; Sentelhas, P.C. Diferença de temperatura mínima do ar medida no abrigo e na relva e probabilidade de sua ocorrência em eventos de geada no Estado de Santa Catarina. Revista Brasileira de Agrometeorologia, Santa Maria, v. 9, n.1, p. 9-15, 2001.

Souza, V.Q. De; Caron, B.O.; Schmidt, D.; Behling, A.; Bamberg, R.; Vian, A.L. Resistência de espécies arbóreas submetidas a extremos climáticos de geada em diferentes sistemas agroflorestais. Revista Ciência Rural, Santa Maria, v.41, n.6, p. 972-977, 2011.

Thom, H.C.S. Some methods of climatological analysis. Geneva, World Meteorological Organization (Technical Note, 81), 1966. 53 p.

U.S. Geological Survey - SURVEY NATIONAL MAPPING DIVISION. Global 30 arc second elevation data. 1999. Disponível em: <http://edcwww.cr.usgs.gov/landdaac/gtopo30/gtopo30.html>. Acesso em: 10 julho 2011.

Wrege, M. S. et al. Atlas Climático da Região Sul do Brasil: Estados do Paraná, Santa Catarina e Rio Grande do Sul. 1. ed. Pelotas: Embrapa Clima Temperado, 2011. v. 1. 332 p.

Wrege, M. S; Fritzsons, E. Dados climáticos dos municípios da região Sul do Brasil [recurso eletrônico] / Colombo: Embrapa Florestas, 2015. (Documentos / Embrapa Florestas, ISSN 1980-3958; 290.

Wrege, M.S.; Caramori, P.H.; Gonçalves, A.C.A. et al. Ocorrência da primeira geada de outono e última de primavera no Estado do Paraná. Revista Brasileira de Agrometeorologia, Santa Maria, v. 12, n. 1, p. 143-150, 2004.

Zaicovski, M.B.; Guetter, A.K.; Quadro, M.F.L. Monitoramento e previsão climática de geadas no Paraná. In: Congresso Brasileiro de Meteorologia. p. 1148-1155, 2008. 